\title{
Changes in Excitability Properties of Ventromedial Motor Thalamic Neurons in 6-OHDA Lesioned Mice
}

\author{
Edyta K. Bichler, Francesco Cavarretta, and ${ }^{-D i e t e r ~ J a e g e r ~}$
}

https://doi.org/10.1523/ENEURO.0436-20.2021

Department of Biology, Emory University, Atlanta, GA 30322

\begin{abstract}
The activity of basal ganglia input receiving motor thalamus (BGMT) makes a critical impact on motor cortical processing, but modification in BGMT processing with Parkinsonian conditions has not be investigated at the cellular level. Such changes may well be expected because of homeostatic regulation of neural excitability in the presence of altered synaptic drive with dopamine depletion. We addressed this question by comparing BGMT properties in brain slice recordings between control and unilaterally 6-hydroxydopamine hydrochloride (6-OHDA)-treated adult mice. At a minimum of one month after 6-OHDA treatment, BGMT neurons showed a highly significant increase in intrinsic excitability, which was primarily because of a decrease in M-type potassium current. BGMT neurons after 6-OHDA treatment also showed an increase in T-type calcium rebound spikes following hyperpolarizing current steps. Biophysical computer modeling of a thalamic neuron demonstrated that an increase in rebound spiking can also be accounted for by a decrease in the M-type potassium current. Modeling also showed that an increase in sag with hyperpolarizing steps found after 6-OHDA treatment could in part but not fully be accounted for by the decrease in M-type current. These findings support the hypothesis that homeostatic changes in BGMT neural properties following 6-OHDA treatment likely influence the signal processing taking place in the BG thalamocortical network in Parkinson's disease.
\end{abstract}

Key words: basal ganglia; hydroxydopamine; m-current; parkinsonian; slice; whole cell

\section{Significance Statement}

Our investigation of the excitability properties of neurons in the basal ganglia input receiving motor thalamus (BGMT) is significant because they are likely to be different from properties in other thalamic nuclei because of the additional inhibitory input stream these neurons receive. Further, they are important to understand the role of BGMT in the dynamic dysfunction of cortico-BG circuits in Parkinson's disease. We provide clear evidence that after 6-hydroxydopamine hydrochloride (6-OHDA) treatment of mice important homeostatic changes occur in the intrinsic properties of BGMT neurons. Specifically, we identify the M-type potassium current as an important thalamic excitability regulator in the parkinsonian state.

\section{Introduction}

The basal ganglia (BG) form strong connections with motor and premotor cerebral cortical areas through output from the substantia nigra pars reticulata (SNr) and internal globus pallidus (GPi; Alexander et al., 1986; Alexander and Crutcher, 1990). These BG outputs terminate as GABAergic inhibitory connections in the motor thalamus, in rodents primarily in the ventromedial (VM)

\footnotetext{
Received October 11, 2020; accepted January 24, 2021; First published January 28, 2021.

The authors declare no competing financial interests.
}

and ventroanterior (VAL) nuclei (VM/VAL; Beckstead et al., 1979; Kuramoto et al., 2009, 2011; Bosch-Bouju et al., 2013). We refer to this as the $B G$ input receiving motor thalamus (BGMT). Glutamatergic thalamocortical neurons in BGMT project to motor and premotor cortex, where they connect primarily to pyramidal neuron dendrites in layer 1 (Kuramoto et al., 2009, 2015; Guo et al., 2018). In traditional models of $B G$ function, the motor thalamus

Author contributions: E.K.B., F.C., and D.J. designed research; E.K.B. and F.C. performed research; E.K.B. and F.C. analyzed data; E.K.B., F.C., and D.J. wrote the paper. 
acts purely as a relay, and transmits a spike rate code by which excessive movement is suppressed through tonic $B G$ inhibition of motor thalamus (Alexander and Crutcher, 1990). In Parkinson's disease, SNr and GPi activity was posited to be increased through an imbalance in direct and indirect pathway striatal input, resulting in thalamic hypoactivity and consequent inability to initiate and perform movements (Albin et al., 1989; Alexander and Crutcher, 1990; DeLong, 1990).

More recently, the BGMT has become recognized more of an integration center in its own right and is considered to actively process synaptic input from multiple sources instead of just transmitting a rate code (Bosch-Bouju et al., 2013). In mice, a closed excitatory loop between VM and anterolateral motor cortex (ALM) was found to be essential to allow movement initiation (Guo et al., 2017), and this loop could be gated by BG output (Catanese and Jaeger, 2020). The question of how in this integration framework the BGMT thalamus is engaged in mediating circuit dysfunction in Parkinson's disease remains unanswered.

Thalamic neurons possess a strong T-type calcium current, which enables rebound bursting and could be involved in normal and pathologic patterns of synaptic integration in rodents (Kim et al., 2017) and primates (Devergnas et al., 2016). Thalamic neurons are also heavily modulated through cholinergic and adrenergic input in their excitability state between waking and sleep modes (McCormick and Prince, 1986; McCormick, 1989). Given a near universal presence of homeostatic regulation of neural excitability in different neural circuits (Davis, 2006; Turrigiano, 2011), an increased inhibitory rate of BG input to BGMT during parkinsonian conditions is likely to engage such mechanisms, which could lead to an increase in excitability. In a series of elegant studies, Bevan and colleagues showed that such homeostatic plasticity exists in the subthalamic nucleus (STN) in 6-hydroxydopamine hydrochloride (6-OHDA) lesioned mice where it counteracts reduced input from globus pallidus (Wilson and Bevan, 2011; Fan et al., 2012). This plasticity may be maladaptive in terms of motor function, however, and result in pathologically correlated activity (Chu et al., 2015; Mclver et al., 2019).

To test the hypothesis that BGMT neurons show changes in excitability in a parkinsonian condition, we obtained whole-cell recordings from BGMT neurons in slices

This work was supported by National Institute of Neurological Disorders and Stroke Grants P50-NS098685 (to D.J., Project 1 PI, Wichmann, Center PI) and 1R01NS111470 (to D.J.)

E. K Bichler's present address: Department of Physiology, Emory University School of Medicine, Atlanta, GA 30322.

Acknowledgements: We thank the considerable help provided by the anatomy core of the Emory Udall center and specifically Dr. Adriana Galvan and Susan Jenkins. We also thank Dr. Su Li for supporting MATLAB code development for data analysis.

Correspondence should be addressed to Dieter Jaeger at djaeger@ emory.edu.

https://doi.org/10.1523/ENEURO.0436-20.2021

Copyright (C) 2021 Bichler et al.

This is an open-access article distributed under the terms of the Creative Commons Attribution 4.0 International license, which permits unrestricted use, distribution and reproduction in any medium provided that the original work is properly attributed. of adult mice and compared neuronal excitability between a control group and mice with unilateral 6-OHDA lesions. In support of our hypothesis, we identified an increase in excitability of BGMT neurons in 6-OHDA lesioned mice, which was primarily because of a decrease in M-type potassium current. In the course of our studies, we also for the first time characterized multiple aspects of intrinsic excitability of BGMT neurons in both normal and 6-OHDA lesioned mice that likely is essential in supporting closed loop thalamocortical excitation.

\section{Materials and Methods}

\section{Animals}

All animal procedures were approved by the Emory IACUC and adhered to the NIH Guide for the Care and Use of Laboratory Animals. Male and female C57BL/6J (IMSR catalog \#JAX:000664, RRID:IMSR_JAX:000664), Vgat-IRES-Cre mice (S/c32a1) aged 1-17 months $(n=38)$ were used for terminal brain slice experiments. Of these mice 12 had been unilaterally 6-OHDA lesioned 110 months (mean period \pm SEM, $4.7 \pm 0.8$ months) before the experiment.

\section{Viral vector injections}

Before surgery slow-release buprenorphine SR (1 mg/ $\mathrm{kg}$, ZooPharm) was administered subcutaneously to reduce pain as long-lasting analgesic. Mice were anesthetized with isoflurane (induction at $3-4 \%$ concentration and maintained at $1-2 \%$ ) and head-fixed on a stereotaxic frame (Kopf Instruments). Ophthalmic ointment was applied to prevent corneal dehydration and a heating pad was used to maintain temperature at $37^{\circ} \mathrm{C}$. A skin incision was made that allowed to perform craniotomies above ALM and SNr unilaterally on the right side of brain. To label GABAergic SNr terminals in BGMT with green fluorescence, $200-300 \mathrm{nl}$ of rAAV2/hsyn-EYFP was injected with a nanoinjector (Nanoinject III, Drummond Scientific) at the average rate of $0.33 \mathrm{nl} / \mathrm{s} \mathrm{(total} 300 \mathrm{nl}$ during $15 \mathrm{~min}$ ) into the SNr targeting the Paxinos mouse atlas (Franklin and Paxinos, 2008) coordinates (in $\mathrm{mm}$ from bregma): AP -3.2, ML 1.6, DV -4.4. To label ALM terminals in BGMT with red fluorescence and express ChR2 in the same terminals, rAAV2/Camklla-hChR2(T159C)-mCherry-WPRE was injected (at volume $300 \mathrm{nl}$ ) into the ALM cortex targeting the Paxinos coordinates (in $\mathrm{mm}$ from bregma): AP 2.5, ML 1.5, DV -1.0 of some animals. This enabled us to subsequently selectively visualize the nigral and ALM terminal fields in BGMT and record from neurons within this field. It also allowed the stimulation of ALM synaptic inputs in brain slice experiments to characterize synaptic inputs (data not ready for publication). After surgery, bacitracin ointment was applied to the region around the incision. Mice were weighed daily and assessed for health and comfort for $4 \mathrm{~d}$ postsurgery.

\section{6-OHDA treatment}

In a separate group C57BL/6J $(n=11)$, and one VgatIRES-Cre mouse (S/c32a1 were injected with $1 \mu \mathrm{l}$ of 6OHDA into the medial forebrain bundle (-1.2 AP, 1.2 ML, 
$-4.75 \mathrm{DV})$ using the procedure described in Lundblad et al. (2004). Briefly, $0.02 \%$ ascorbic acid was added to a sterile saline solution $(\mathrm{NaCl}, 0.9 \% \mathrm{w} / \mathrm{v})$ and $6-\mathrm{OHDA} \mathrm{HCl}$ powder (6-OHDA from Sigma or 6-OHDA hydrobromide from Tocris) was then dissolved to produce a final $6-O H D A$ concentration of $4.44 \mathrm{mg} / \mathrm{ml}$. This method produced strong nigrostriatal lesioning as verified histologically through TH antibody staining (see immunohistochemistry below).

\section{Slice preparation and solutions}

On each experimental day, a mouse was deeply anesthetized with isoflurane and transcardial perfusion was performed with icy cold choline chloride solution containing the following: $117 \mathrm{~mm} \mathrm{ChCl,} 2.5 \mathrm{~mm} \mathrm{KCl}, 1.25$ $\mathrm{mm} \mathrm{NaH} \mathrm{PO}_{4}, 26 \mathrm{~mm} \mathrm{NaHCO} 3,10 \mathrm{~mm}$ dextrose, $0.5 \mathrm{~mm}$ $\mathrm{CaCl}_{2}, 7 \mathrm{mM} \mathrm{MgCl}_{2}, 1.0 \mathrm{~mm}$ sodium pyruvate, and $1.3 \mathrm{~mm}$ L-ascorbic acid, which was bubbled with 95\% $\mathrm{O}_{2}-5 \% \mathrm{CO}_{2}$. Mouse decapitation was performed with scissors, and the brain was quickly removed, immersed in cold choline chloride solution, and mounted on the flat surface of the microtome tray (Microm HM 650). Coronal thalamic slices $(250 \mu \mathrm{m}$ thick) were prepared and put to recover in a holding chamber in regular artificial CSF (ACSF) at $32^{\circ} \mathrm{C}$ for $20 \mathrm{~min}$ followed by room temperature. The ACSF contained the following: $124 \mathrm{~mm} \mathrm{NaCl}, 2.5 \mathrm{~mm}$ $\mathrm{KCl}, 1.25 \mathrm{~mm} \mathrm{NaH}_{2} \mathrm{PO}_{4}, 26 \mathrm{~mm} \mathrm{NaHCO} 3,10 \mathrm{~mm}$ glucose, $2 \mathrm{mM} \mathrm{CaCl}_{2}$, and $1.3 \mathrm{mM} \mathrm{MgCl}_{2}$. Chemicals were purchased from Sigma or Abcam.

Individual slices were transferred to a recording chamber and continuously superfused with oxygenated ACSF at $26-28^{\circ} \mathrm{C}$ at a flow rate of $2.5 \mathrm{ml} / \mathrm{min}$. The BGMT region was visually identified by video microscopy (Olympus model BX51WI outfitted with differential interface contrast and an IR sensitive Dage MTI camera attached to the recording setup) by mcherry expression because of cortical glutamatergic afferents projecting to BGMT neurons following AAV injection into ALM and by proximity to the $\mathrm{mt}$ fiber bundle. Neurons in slices without terminal label $(n=1$ mouse in 6-OHDA-treated group, and $n=17$ mice in control group) were localized to BGMT according to matching their location with those find in labeled slices by proximity to the mt fiber bundle at the matching AP level (Franklin and Paxinos, 2008). Thereafter, whole-cell patch-clamp recordings were obtained at the soma under $60 \times$ magnification in BGMT neurons from control and 6-OHDAlesioned mice with glass pipettes (at resistances 4-8 M 2 ) pulled from 1.5-mm OD borosilicate glass on a Sutter P-97 puller (Sutter Instruments).

\section{Determination of intrinsic excitability}

To compare intrinsic excitability between 6-OHDAtreated and control mice, we assessed hyperpolarizationactivated current $\left(\mathrm{I}_{H}\right)$, muscarine-sensitive potassium current $\left(\mathrm{I}_{\mathrm{M}}\right), \mathrm{I}_{\mathrm{T}}-\mathrm{Ca}^{2+}$ current contributions to membrane potential trajectories. Current traces were recorded in whole-cell current clamp mode using a K-gluconate pipette solution containing the following: $130 \mathrm{~mm}$ K-gluconate, $10 \mathrm{~mm} \mathrm{NaCl}, 10 \mathrm{~mm} \mathrm{KCl}, 10 \mathrm{~mm}$ HEPES, $1 \mathrm{~mm}$
$\mathrm{MgCl}_{2}$, $0.5 \mathrm{~mm}$ Na-GTP, $1 \mathrm{~mm}$ Mg-ATP, 5 mм phosphocreatine, $0.1 \mathrm{~mm}$ spermine, $0.2 \mathrm{~mm}$ EGTA; titrated to $\mathrm{pH} 7.2$ with $\mathrm{KOH}$. The junction potential of this intracellular solution used for current-clamp with respect to the ACSF was calculated with JPcalc (Barry, 1994), and had a value of $14.2 \mathrm{mV}$. It was not subtracted from the measurements reported. Depolarizing and hyperpolarizing command current pulses at various duration and amplitude were injected into recorded somata via the patch pipette. To prevent spontaneous network firing, synaptic blockers of glutamatergic signaling DNQX $(10 \mu \mathrm{M})$ and D-AP5 $(50 \mu \mathrm{M})$ were included in the patch-clamp superfusion. A subset of neurons was exposed to the specific M-channel blocker XE-991 dihydrochloride (10-20 $\mu \mathrm{M})$ added to the bath after washing-in control ACSF to evaluate the role of Mtype potassium channels in modulating 6-OHDA-induced hyperexcitability. While whole-cell configuration was established, each neuron was not stimulated for at least $5 \mathrm{~min}$. Cells were included in the data if the resting membrane potential $\left(V_{\text {Rest }}\right)$ was at least $-55 \mathrm{mV}$.

Data acquisition was performed using a Multi Clamp Amplifier 700B in conjunction with a customized LabVIEW (National Instruments) software interface. Whole-cell patch clamp recordings were low-pass filtered at $10 \mathrm{kHz}$ and digitized at $20 \mathrm{kHz}$. All analysis of electrophysiological data were performed using custom protocols using MATLAB (MathWorks).

To evaluate intrinsic excitability, neurons were injected with depolarizing current pulses (ranging from 20 to 260 pA; $2000 \mathrm{~ms}$ in duration). The $\mathrm{V}_{\text {Rest }}$ of BGMT neurons typically was hyperpolarized enough so that a small depolarizing current injection would trigger a single low-threshold spike (LTS) burst. To deactivate the underlying T-type $\mathrm{Ca}^{2+}$ current, a bias current (CON: 59.8 pA [25.1,246.7], $n=19$; 6OHDA: 45.3pA [-99.6,150.5], $n=17$; Mann-Whitney test, $p=0.04)$ was applied (CON: $-57.2 \mathrm{mV}[-64.1,-52.7]$, $n=19$; 6-OHDA: $-54.8 \mathrm{mV}$ [-69.2,-50.2], $n=17$; MannWhitney test, $p=0.12)$ to achieve the desired membrane voltage (Jahnsen and Llinás, 1984a,c; Lundblad et al., 2004). The action potential firing frequency was calculated for each current step on top of the applied bias. Only action potentials that occurred at $50 \mathrm{~ms}$ or longer after the onset of the step current injection were included in the analysis (Dougherty et al., 2012). F-I curves (frequency of action potential firing as a function of injected current) were constructed. The rheobase was determined as the current amplitude at which a linear fit to the F-I curve evoked $3-\mathrm{Hz}$ action potential firing. To measure input resistance $\left(\mathrm{R}_{\text {in }}\right)$, a hyperpolarizing -10-pA pulse current of $100 \mathrm{~ms}$ was applied and the voltage response amplitude was measured at $100 \mathrm{~ms}$. The membrane time constant was determined based on voltage responses to -1-nA current pulse injection of $0.5-\mathrm{ms}$ duration, and calculated as elapsed time required for the evoked voltage response to decay back to $33 \%$ of the peak amplitude. The action potential voltage threshold $\left(\mathrm{V}_{T}\right)$ was determined as the measured voltage where the value of $\mathrm{dV} / \mathrm{dt}$ exceeded $10 \mathrm{mV} / \mathrm{ms}$ at the first AP in response to a 2000-ms current step of minimal amplitude to elicit APs (Dougherty et al., 2012). To evaluate $I_{H}$ hyperpolarizing current steps (range -200 to 
$-50 \mathrm{pA}$; 50-pA increment, 2000-ms duration) were applied in current clamp mode at the $\mathrm{V}_{\text {Rest }}$ (mean $\pm \mathrm{SEM}$; $-62.7 \pm 0.8 \mathrm{mV}$; for CON and 6-OHDA all together). Percentage sag was measured as $100^{*}\left(1-\mathrm{V}_{\mathrm{ss}} / \mathrm{V}_{\text {peak }}\right)$, where $V_{s s}$ was the steady-state voltage deflection from baseline at $2000 \mathrm{~ms}$ after pulse onset, and $V_{\text {peak }}$ was the peak negative voltage deflection from baseline (Narayanan and Johnston, 2007). To reveal effects of 6-OHDA treatment on rebound firing, hyperpolarizing current steps (range, $-500,-50$ pA, $50-p A$ increment, and 200,500 or 2000-ms duration) were applied in current clamp mode. The baseline membrane potential at the time of applying steps on average was $-56.5 \mathrm{mV}[-63.7,-50]$ while a bias current (range, $-17.5,210.5 \mathrm{pA}$ ) was applied to stabilize a subthreshold voltage depolarized at this level to avoid T-type channel deinactivation before pulse onset. For each individual voltage trace, the peak deflection and number of action potentials were calculated.

\section{Statistical analysis}

Statistical analysis was performed using Prism 6 (GraphPad Software). Statistical significance between comparisons of two groups was achieved using paired or un-paired $t$ test for data that was normally distributed (as measured by either Pearson or Shapiro-Wilk normality test). When data were not normally distributed, Wilcoxon matched-pairs signed-rank tests or unpaired MannWhitney $U$ tests were administered. Comparison of sag amplitude between control and 6-OHDA treated mice was performed using a two-way ANOVA on sag amplitude by current injection level (Fig. 3B, Table 2). Normally distributed data are presented as mean \pm SEM in the text and parametric tests are performed, whereas skewed data are presented as medians with quartiles, and non-parametric tests are performed. Effect sizes are given in differences between means when parametric tests are used, and in difference between medians for non-parametric tests. Statistically significant differences are represented on figures by asterisks. ${ }^{*} p<0.05,{ }^{* *} p<0.01,{ }^{* * *} p<0.001$, and ${ }^{* \star * \star} p<0.0001$. Box and whisker plots represent medians, quartiles, and 5th-95th percentiles with solid horizontal lines. The sample mean is shown in box plots as horizontal dotted line.

\section{Immunohistochemistry for tyrosine hydroxylase (TH) and quantification of nigrostriatal innervation}

Coronal sections (150-200 $\mu \mathrm{m}$, obtained during preparation of slices for electrophysiology) were submerged in $4 \%$ paraformaldehyde in $0.1 \mathrm{M} \mathrm{PB}$. The sections were then embedded in $0.5 \%$ gelatin in distilled water, and the gelatin block was immersed again in $4 \%$ paraformaldehyde overnight. The tissue was then sectioned to $40-\mathrm{mm}$ coronal sections using a vibrating microtome (Leica) the gelatin embedded sections were cut into $40-\mathrm{mm}$ sections and stored at $-20^{\circ} \mathrm{C}$ in antifreeze solution. To verify denervation of the nigrostriatal pathway induced by 6OHDA treatment, sections at the level of the striatum were pretreated with $1 \%$ normal goat serum, $1 \%$ bovine serum albumin and $0.3 \%$ Triton $\mathrm{X}-100$, and then incubated in rabbit anti-TH antibody solution (Millipore catalog \#AB152, 1;300) overnight. This was followed by incubation in secondary biotinylated antibodies, then in Avidin-biotin-peroxidase complex (ABC) solution (1:200; Vectastain standard kit, Vector) for $90 \mathrm{~min}$. The sections were then placed in $0.025 \% 3-3$ '-diaminobenzidine tetrahydrochloride (DAB; Sigma-Aldrich), $0.01 \mathrm{~m}$ imidazole (Fisher Scientific), and $0.006 \% \mathrm{H}_{2} \mathrm{O}_{2}$ for $10 \mathrm{~min}$. All incubations were done at room temperature. The sections were mounted on slides, cover-slipped, and digitized with an Aperio Scanscope CS system (Leica).

To quantify the loss of nigrostriatal innervation, the optical density of $\mathrm{TH}$-stained areas was measured in the striatum of the lesioned hemisphere of 6-OHDA-treated animals, and these values compared against the striatal optical density from the contralateral hemisphere of the same slice using ImageJ. The scanned images were corrected for brightness, converted into 16-bit grayscale format and inverted. For each animal, measurements of the optical density were obtained in the dorsolateral striatum in two sections (approximately at anteroposterior planes -0.7 and $0.1 \mathrm{~mm}$ from bregma, according to Franklin and Paxinos, 2008). To control for differences in background staining, the optical density measured in the corpus callosum was subtracted from the striatal measurements.

\section{Computer simulations}

The simulations were conducted with an integrated NEURON (v.7.7) + Python (v.3.7) environment (Hines and Carnevale, 1997), with an adaptive time-step integration, i.e., Cvode solver. The simulated temperature was $27^{\circ} \mathrm{C}$ as the average value given by the experiments. The model source code will be publicly available on the Senselab ModelDB (http://senselab.med.yale.edu) and GitHub (https:// github.com/FrancescoCavarretta/VMThalamocorticalNeuron Model) on publication.

The thalamocortical cell (TC) was implemented as a multicompartmental biophysically- detailed model that replicates the full dendritic tree and firing behaviors that characterize the TCs of the BGMT thalamus.

\section{Morphology}

We used a morphologic reconstruction of a VM nucleus TC belonging to the Janelia MouseLight Dataset (https:// www.janelia.org/project-team/mouselight; id. AA0136). Although these VM morphologies included full reconstructions of the axon, we retained only the initial $70 \mu \mathrm{m}$ of it, which is putatively the axon initial segment (AIS). Therefore, the morphology of our TC model was comprised of three subcellular sections, the soma, the dendrites, and the AIS. The experimental procedure used for reconstructing the MouseLight morphologies did not allow to measure the diameters of the neurites. We therefore fixed the diameter of the AIS to $1.5 \mu \mathrm{m}$; the soma was replaced with a single compartment of $293 \mu \mathrm{m}^{2}$ in surface (Sawyer et al., 1989); and we defined a model for the dendritic diameters based on the 2/3 Rall' Power Law, of which parameters were directly estimated from eight reconstructions of BGMT TCs from the physiological dataset presented in this study. 
Table 1: Subcellular distributions of ion channels in thalamocortical neuron model

\begin{tabular}{|c|c|c|c|c|c|}
\hline \multicolumn{4}{|c|}{ AIS } & \multicolumn{2}{|c|}{ Dendrites } \\
\hline Channel & Distal & Proximal & Soma & 1st order & 2nd order or above \\
\hline $\mathrm{NaP}$ & 0.0019 & 0.0001 & 0.0001 & 0.0001 & 0.0001 \\
\hline $\mathrm{KA}$ & 0.005 & 0.095 & 0.005 & 0.005 & 0.005 \\
\hline KM & 0.0165 & 0.00033 & 0.00033 & 0.00033 & 0.00033 \\
\hline $\mathrm{CaL}$ & 0.0041 & 0.0041 & 0.0041 & 0.00205 & 0.00205 \\
\hline $\mathrm{Ca}_{\mathrm{T}}$ & 0 & 0 & 0.000085 & 0.00017 & 0.0000425 \\
\hline $\mathrm{I}_{\mathrm{H}}$ & 0 & 0 & 0.000035 & 0.000035 & 0.000035 \\
\hline
\end{tabular}

Number given in units of $\mathrm{S} / \mathrm{cm}^{2}$.

\section{Membrane properties}

The passive parameter values were given by a uniform specific membrane resistivity ( $\mathrm{rm}$ ) of $26.0 \mathrm{M} \Omega / \mathrm{cm}^{2}$, cytoplasmic resistivity (ri; i.e., intracellular or axial resistivity) of $60.0 \Omega \mathrm{cm}$, specific membrane capacitance $(\mathrm{cm})$ of $1.0 \mu \mathrm{F} /$ $\mathrm{cm}^{2}$ (Gentet et al., 2000), and resting potential $\left(\mathrm{V}_{\text {Rest }}\right)$ of $-75.75 \mathrm{mV}$. To simulate the firing behavior of BGMT TCs, we distributed 10 classes of active membrane conductances along the TC morphology (Table 1). The active conductances were $\mathrm{NaF}$ (i.e., sodium channels that are not Nav1.6 types), NaP (i.e., Nav1.6 type), KDR, KA, $\mathrm{I}_{\mathrm{H}}$, CaT, CaL, SK (i.e., small-conductance calcium-activated sodium channels), $I_{M}$ (i.e., Kv7), and ANO2-CaC channels (i.e., calcium-activated chloride channels). The models of $\mathrm{NaF}, \mathrm{KDR}, \mathrm{KA}, \mathrm{I}_{\mathrm{H}}, \mathrm{CaT}, \mathrm{CaL}$, and SK channels were imported from a previously published model of ventrobasal (VB) thalamocortical neurons (lavarone et al., 2019). To match our measures of the sag amplitude, we shifted the inactivation curve by $-11 \mathrm{mV}$ for the $\mathrm{I}_{H}$ channel. This alteration made the sag amplitudes increasing monotonically with hyperpolarizing currents between -50 and $-200 \mathrm{pA}$. Indeed, without this alteration, the sag amplitude was lower with current injection of $-200 \mathrm{pA}$ than $-150 \mathrm{pA}$. We derived the $\mathrm{NaP}$ from the $\mathrm{NaF}$ shifting the activation and inactivation curves by $14 \mathrm{mV}$ (Hu et al., 2009). We based the $I_{M}$ channel on experimental data of neocortical pyramidal cells (Battefeld et al., 2014), adding a constant term (of 0.025 ) to the equation of activation $(\mathrm{m})$ :

$$
m(v)=0.025+\frac{1}{1+\exp \left(\frac{v+36.7}{9.48}\right)} .
$$

This alteration of the original equation increased the opening fraction of $I_{M}$ channels, which decreased the $\mathrm{V}_{\text {Rest }}$ of the TC model to our physiological values. We implemented a model of ANO2-CaCC channel based on the experimental data of Pifferi et al. (2009), using a reversal potential of $-86 \mathrm{mV}$. This channel is responsible for early firing rate adaptation in TC neurons (Ha et al., 2016). The ionic subcellular distribution of each ion channel resulting in a good match with the physiological recordings based on manual tuning are given in Table 1. In the TC model, intracellular calcium was structured in three separate microdomains with distinct decay constants. In particular, calcium flowing through CaL channel bound with two microdomains with different percentages ( $25.8 \%$ and $74.2 \%)$, activating SK and ANO2-CACC channels (decay time constant: 14 and $50 \mathrm{~ms}$, respectively). Instead, calcium flowing through CaT channel bound with a third microdomain (decay time constant: $50 \mathrm{~ms}$ ), without activating ion channels (Womack et al., 2004).

\section{Analysis of model cell properties}

To compare the passive cell properties of our BGMT TC model to our physiological recordings, we simulated somatic current injections. Simulations were necessary for their measurements, as they resulted of the nonlinear combination between morphologic features, passive properties, along with the configuration and the dynamics of the active membrane conductances. To measure the $\mathrm{R}_{\text {in }}$, we simulated a hyperpolarizing injection of $-10 \mathrm{pA}$ for $100 \mathrm{~ms}$, calculating the Rin as the deviation from the resting potential, measured at $100 \mathrm{~ms}$, divided by the current intensity. We thus estimated a $R_{\text {in }}$ of $218.2 \mathrm{M} \Omega$. To measure the membrane time constant $(\tau)$, we used a double exponential fitting $[\mathrm{a} \cdot \exp (\mathrm{t} / \tau 1)+\mathrm{c} \cdot \exp (\mathrm{t} / \tau 2)]$ to the decaying phase of the membrane voltage observed with a hyperpolarizing current pulse of $-1 \mathrm{nA}(0.5 \mathrm{~ms})$. The membrane time constant then corresponded to the time constant of the slowest exponential term. We thus estimated that $\tau$ was $19.1 \mathrm{~ms}$ for our TC model, consistent with our experimental measures. The cell capacitance $(C)$ was calculated as the ratio between $\tau$ and $\mathrm{R}_{\text {in }}$, and resulting in an estimate of $87.4 \mathrm{pF}$, consistent with our experimental measures. Finally, the $\mathrm{V}_{\text {Rest }}$ was $-77.3 \mathrm{mV}$, which was consistent with our experimental measures of $-65 \mathrm{mV}$ given the junction potential of $-14.2 \mathrm{mV}$.

\section{Results}

The goal of our study was to determine any changes in neural properties in the area of motor thalamus that receives $B G$ input (BGMT) in mice unilaterally treated with $6-O H D A$ in the median forebrain bundle as a standard rodent model of robust dopamine neuron lesioning. To this end, we obtained brain slice recordings of BGMT neurons from a total of 26 control mice and of 126 -OHDA-treated mice. The BGMT was either defined through fluorescent label of nigral GABAergic input or through location with 
A
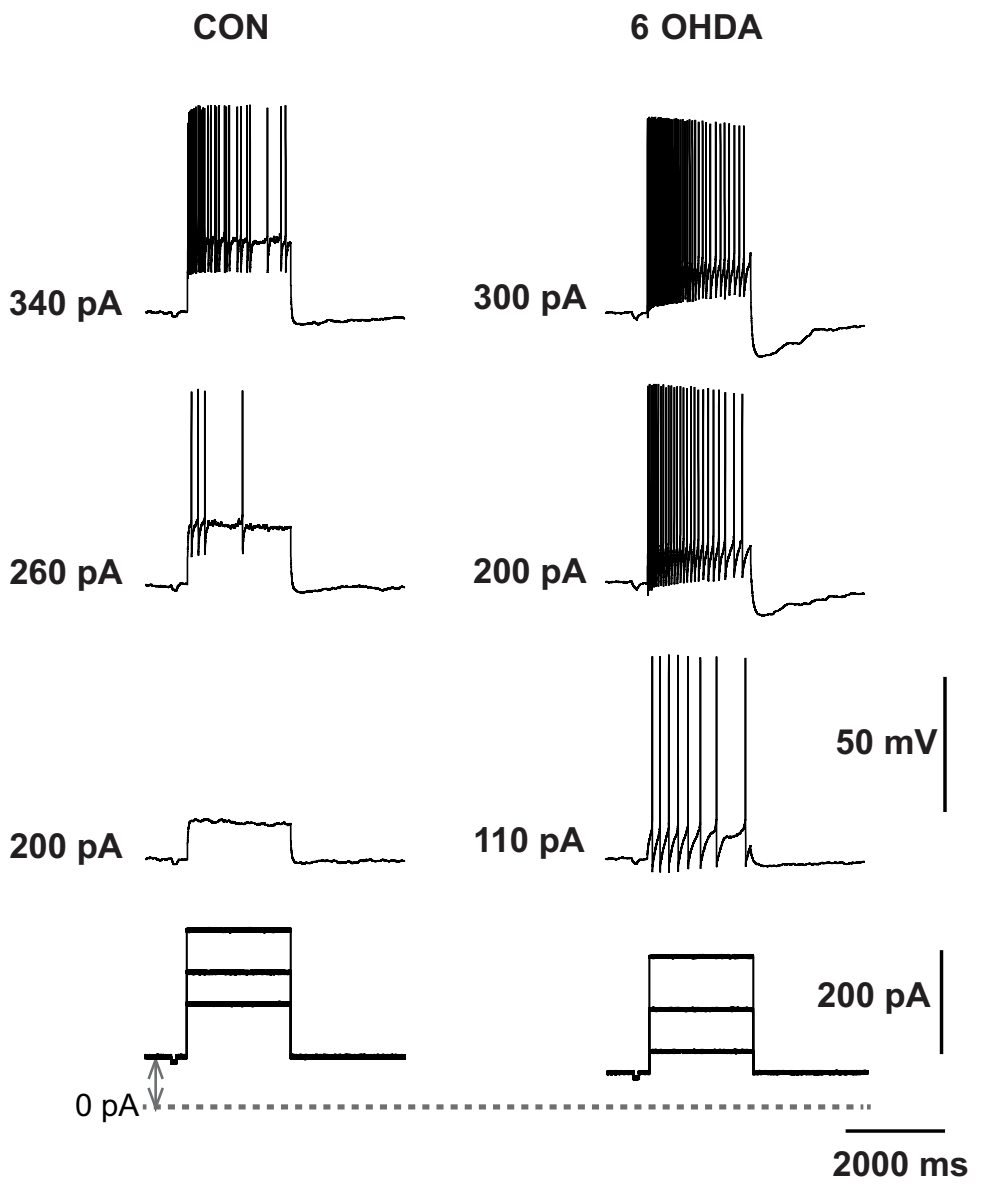

B
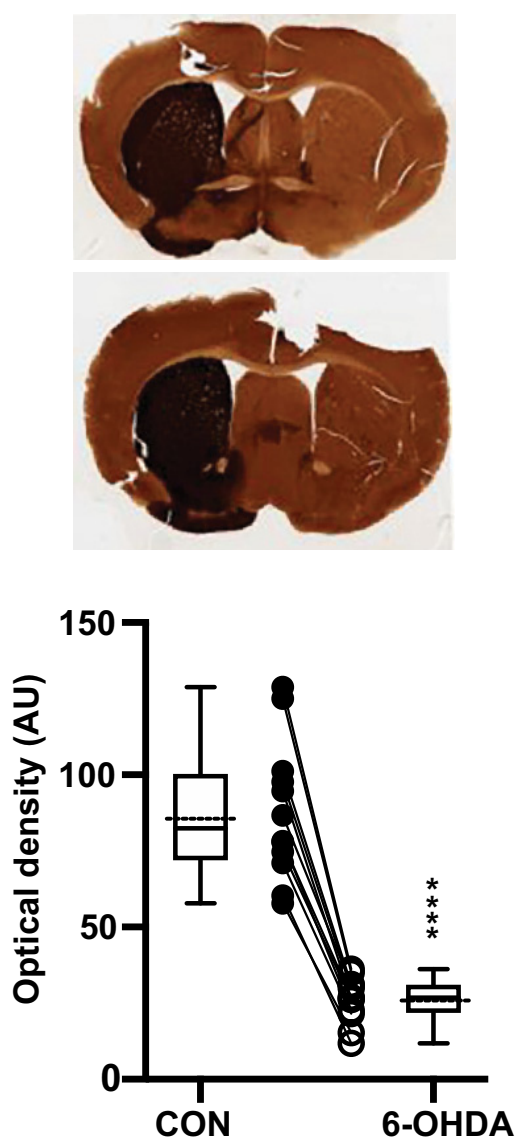

C

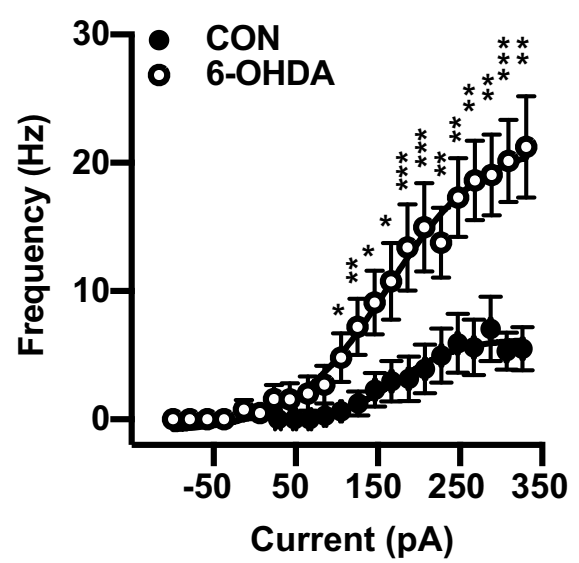

E

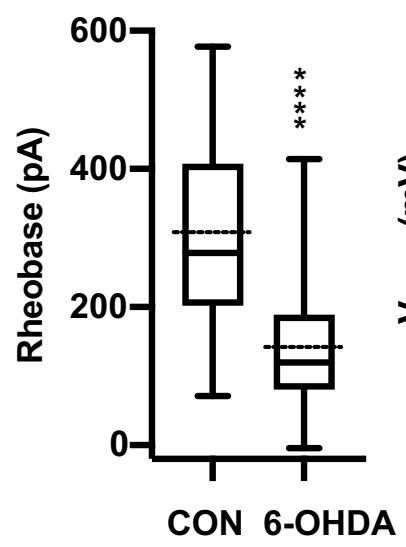

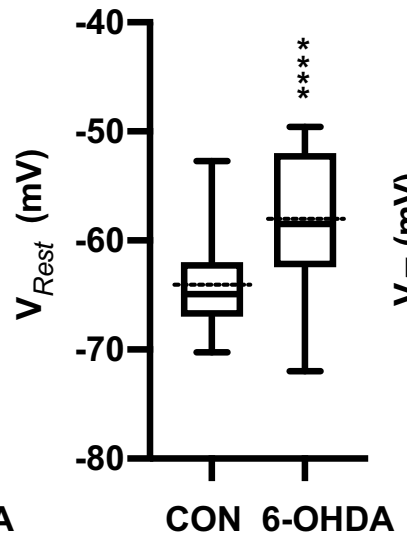

Figure 1. 6-OHDA induced dopamine depletion elicits hyperexcitability in ventral motor thalamus region. $\boldsymbol{A}$, Characteristic voltage responses to increasing current injections (bottom) recorded in a representative neuron of control mouse (CON, left upper panel) and of mouse 20 weeks after injection with 6-OHDA (right upper panel). To block glutamatergic and GABAergic synaptic inputs, DNQX (AMPA/kainate receptor antagonist, $10 \mu \mathrm{M})$, D-AP5 (NMDA receptor antagonist, $50 \mu \mathrm{M})$, and gabazine (10 $\mu \mathrm{M})$ were applied in both situations. The dashed line designates the 0-pA level of bias current and up-down gray arrow indicate bias current. In these examples, baseline membrane potentials (CON: $-65 \mathrm{mV}$ and 6-OHDA: $-67 \mathrm{mV}$ ) were depolarized up to $-55 \mathrm{mV}$ by applying bias currents (CON: $100 \mathrm{pA}$ and 6-OHDA: $70 \mathrm{pA}$ ). B, Verification of successful 6-OHDA lesioning was achieved by TH staining. Top panel, Representative digitized images of coronial striatal sections showing example TH staining in control (left) and lesioned (right) hemispheres of two individual mice after administration $1 \mu \mathrm{l}$ of 6 -OHDA solution in the medial forebrain bundle. Top picture shows $68 \%$ decrease in TH immunoreaction of lesioned dorsal striatum compared with the non-lesioned side (27.9 vs $88.6 \mathrm{AU})$ four weeks after 
continued

dopamine injection. At bottom, image of striatum showing $70 \%$ reduction in TH staining (21.6 vs 71.11 AU) 5 months after $6-$ OHDA injection. Bottom panel, On average, TH immunoreactivity calculated based on optical density was significantly higher at non-injected site compared with 6-OHDA-treated side (CON vs 6-OHDA side: $87.8 \pm 6.6$ vs $26.2 \pm 2.1, n=12$; paired $t$ test, $p<0.0001$ ). Individual mice are shown as line plots between the box plots. $\boldsymbol{C}$, Dopamine deficit for 5-40 weeks significantly enhanced firing frequency and shifts the F-I curve to the left (open circles) compared with controls (filled circles; CON: $n=19$ vs 6-OHDA: $n=17$; Mann-Whitney test, $p \leq 0.026)$. The bias given to depolarize neurons up to $-56.1 \mathrm{mV}[-64.9,-50.5]$ to avoid T-type burst spiking was significantly higher for neurons from 6-OHDA-treated than control mice (Mann-Whitney test, $p=0.04$; see Materials and Methods). The data are binned along the $x$-axis every $20 \mathrm{pA}$, as the application of different bias current for different cells did not result in the same exact current injection values for each neuron. Each circle represents mean \pm SEM. $\boldsymbol{D}$, For each individual neuron included in panel $\mathbf{C}$, a Boltzmann sigmoidal fit was done based on injected current-firing rate relationship and tonic rheobase current that induced action potentials firing at $3 \mathrm{~Hz}$ was measured. Average tonic rheobase was significantly reduced by half after dopamine deficit (on right) compared with controls (CON: $n=19$ vs 6-OHDA: $n=17$; Mann-Whitney test, $p=0.0001$ ). $E$, On average, $\mathrm{V}_{\text {Rest }}$ was depolarized $6.4 \mathrm{mV}$ higher in 6-OHDA-treated (CON: $-64.9 \mathrm{mV}$ [-70.3,-52.7], $n=46$ vs 6-OHDA: $-58.5 \mathrm{mV}$ $[-72.0,-49.6], n=31$; Mann-Whitney test, $p<0.0001)$. $\boldsymbol{F}$, Action potential $\mathrm{V}_{T}$ showed significant reduction compared with controls (CON: $n=18$ vs 6 -OHDA: $n=17$; $t$ test, $p=0.0114$; the same set of neurons as in panels $\boldsymbol{C}, \boldsymbol{D}$ ). Box and whisker plots represent medians, quartiles, and 5th-95th percentiles with solid horizontal lines. The sample mean is shown as horizontal dotted line.

Figure Contributions: Edyta K. Bichler conducted experiments, performed statistical analysis, and prepared figure. Dieter Jaeger reviewed data and analysis.

respect to the $\mathrm{mt}$ fiber bundle. We broadly ascertained excitability properties that govern intrinsic neural dynamics in these cells that could be altered in Parkinsonian states because of homeostatic plasticity mechanisms.

\section{Changes in firing frequency-current (F-I) relationships}

Thalamic neurons are well known to have two distinct firing modes, often called burst and tonic firing (Ramcharan et al., 2000). Burst firing is enabled when the membrane is sufficiently hyperpolarized to de-inactivate a T-type calcium current (CaT; Jahnsen and Llinás, 1984b; Gutierrez et al., 2001; Llinás and Steriade, 2006). In awake animals, tonic firing generally predominates because of the depolarizing baseline of synaptic inputs and cholinergic modulation (McCormick and Prince, 1986; Sherman and Guillery, 2002). To compare the tonic firing properties of BGMT neurons between control and 6-OHDA-treated conditions we therefore depolarized whole-cell recordings to a level of $-55 \mathrm{mV}$ with a tonic bias current to inactivate CaT, and added positive current injection pulses on top of this bias current to ascertain the minimum current needed to elicit tonic firing (rheobase), the spike threshold $\left(V_{T}\right)$, and the relationship between injected current amplitude and firing frequency (F-I; Fig. 1). We found a significant difference in all these parameters for neurons obtained from 6-OHDA-treated animals $(n=17$ neurons) compared with neurons obtained from controls ( $n=19$ neurons). BGMT neurons from 6-OHDA-treated mice showed a significantly lower rheobase (Fig. 1D) with an effect size of $-158.9 \mathrm{nA}$ and a $95 \%$ confidence interval $(\mathrm{Cl})$ of $[-235.2,-82.49]$. They also showed a significantly lower spike $\mathrm{V}_{T}$ (Fig. $1 F$ ), with an effect size of $-4.15 \mathrm{mV}$ and a $95 \% \mathrm{Cl}$ of $[-7.32,-0.99]$. Finally, they showed a dramatically higher spike frequency with increasing current injection amplitudes (Fig. 1C) than neurons from control mice. The effect size for the highest level of current injection used in all cells $(326 \mathrm{pA})$ was an effect size of $15.8 \mathrm{~Hz}$ rate increase and a $95 \% \mathrm{Cl}$ of $[8.5,24]$. Without bias current injection, neurons from 6-OHDA-treated mice additionally showed a significantly more depolarized $\mathrm{V}_{\text {Rest }}(p<0.0001, n=46,31)$ than neurons from control mice (Fig. $1 E$ ) with an effect size of
$6.4 \mathrm{mV}$ and a $95 \% \mathrm{Cl}$ of $[3 \cdot 6,9.8]$. These results show our main finding that BGMT neurons in 6-OHDA-treated mice are considerably more excitable by depolarizing input than neurons in control mice.

\section{Passive properties of BGMT neurons in control and 6- OHDA lesioned mice are similar}

We next asked the question of whether any changes in passive properties of BGMT neurons in 6-OHDA lesioned mice might account for the increase in excitability. For example, if such neurons were to shrink in size, they would show a lower capacitance and an increased $R_{\text {in }}$ to make them more excitable with a given amount of current injection. We found, however, that passive properties remained unchanged. Measures of the membrane time constant (Fig. 2A), membrane capacitance (Fig. 2B), and $\mathrm{R}_{\text {in }}$ (Fig. 2C; for details, see Materials and Methods) revealed no significant differences between control and 6OHDA lesioned mice. Membrane capacitance and $R_{\text {in }}$ were distributed between a similar range of values for both conditions and showed an inverse relationship as expected (Fig. 2D). We also plotted the respective distributions of membrane time constant (Fig. 2E), membrane capacitance (Fig. 2F), and $\mathrm{R}_{\text {in }}$ (Fig. 2G), demonstrating a broad and largely overlapping distributions of these parameters.

\section{6-OHDA-treated mice show an increase in sag with hyperpolarizing current injection in a subpopulation of neurons}

The $I_{H}$ associated with cyclic nucleotide gated $(\mathrm{HCN})$ channels has been shown to counteract inhibitory input in subthalamic neurons (Atherton et al., 2010), but also can limit excitatory input (Sheets et al., 2011) and stabilize the membrane potential to prevent bistability (Williams et al., 2002). Further, alteration in $I_{H}$ has been implicated in several disease models, including Alzheimer's disease (Eslamizade et al., 2015), and epilepsy (Noam et al., 2011). A hallmark of $I_{H}$ is that it induces a "sag" in the 
A

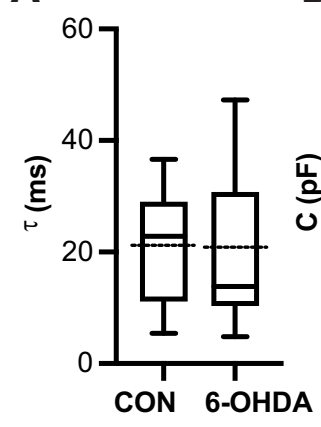

E
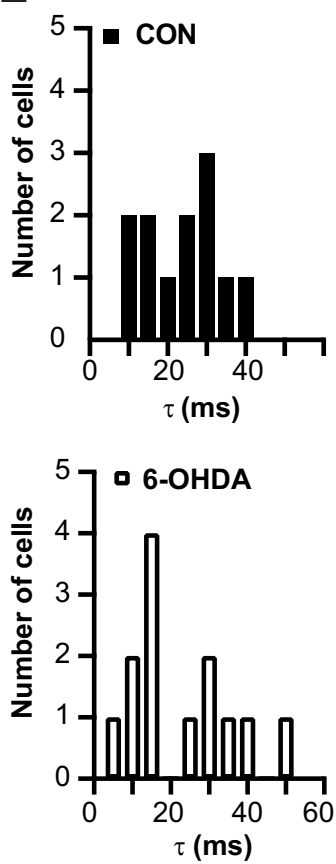

C

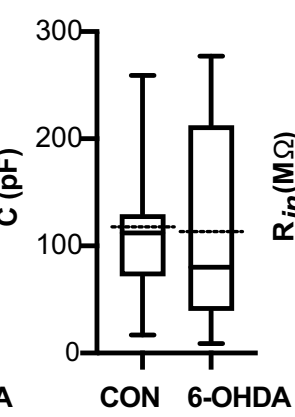

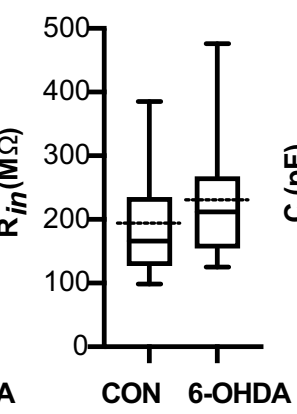

D

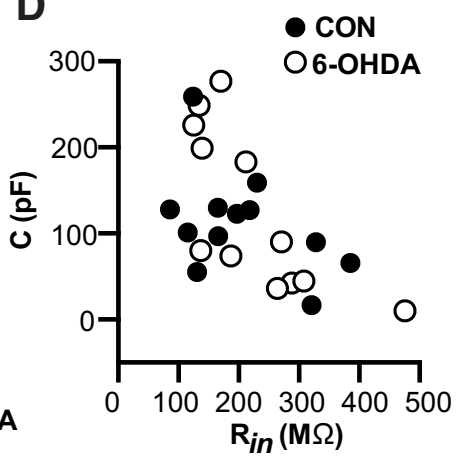

$\mathbf{F}$
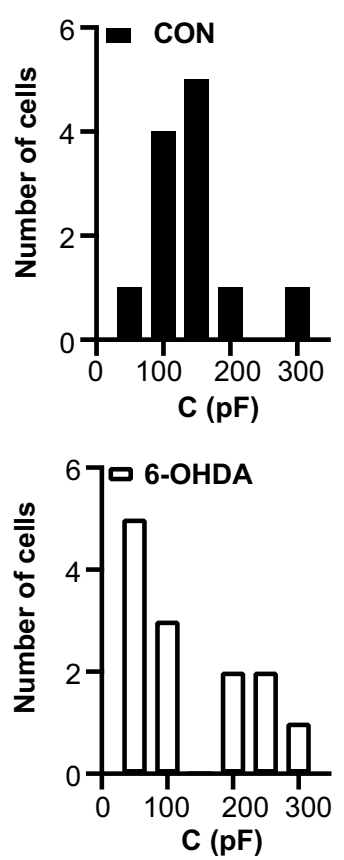

G
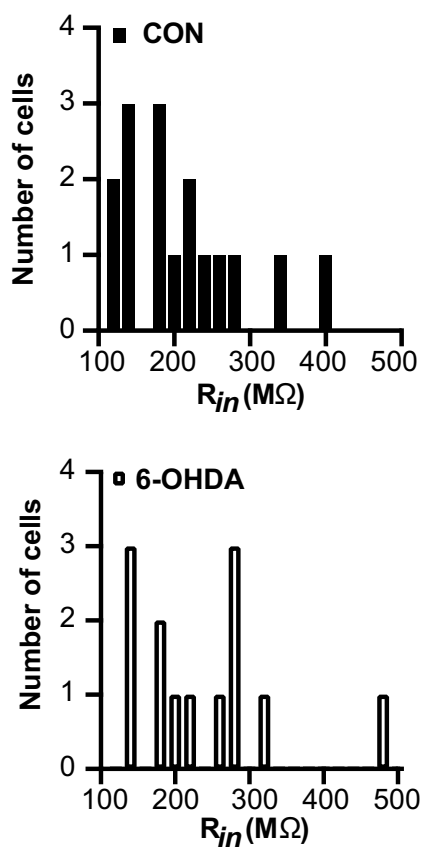

Figure 2. Resting membrane properties remained unchanged after 6-OHDA injection. Electrophysiological passive properties for the data presented in Figure 1. $\boldsymbol{A}-\boldsymbol{C}$, Dopamine depleted hyperexcitable neurons did not shown significant changes in time constant $\tau$ (CON: $20.7 \pm 2.97 \mathrm{~ms}, n=12$; 6-OHDA: $21.04 \pm 3.66 \mathrm{~ms}, n=13$; $t$ test, $p>0.94)$, membrane capacitance (CON: $112.6 \pm 17.4 \mathrm{pF}, n=12$; $6-\mathrm{OHDA}$ : $117.0 \pm 26.6 \mathrm{pF}, n=13$; $t$ test, $p=0.89)$, and $\mathrm{R}_{\text {in }}$ measured at $\mathrm{V}_{\text {Rest }}\left(\mathrm{R}_{\text {in }}\right.$ : $\mathrm{CON}: 166 \mathrm{M} \Omega$ [98.5,385.0], $n=17 ; 6-\mathrm{OHDA}: 212.0 \mathrm{M} \Omega$ [125,476], $n=13$; Mann-Whitney test, $p=0.19$ ). Box and whisker plots represent medians (continous line), quartiles, and 5th-95th percentiles. The dotted protruding line indicates the mean of sample (for details, see Table 2). $\boldsymbol{D}$, In the 6-OHDA mouse model, relationship between membrane capacitance and $R_{\text {in }}$ is comparable to healthy cells in motor thalamus area. Box and whisker plots represent medians, quartiles, and 5th95th percentiles. $\boldsymbol{E}-\mathbf{G}$, Histograms of data presented in panels $\boldsymbol{A}-\boldsymbol{C}$ for controls (on top) and after treatment (bottom). Individual histograms represent distribution of $\tau$, capacitance, and $\mathrm{R}_{\text {in }}$ data based on bin width $5 \mathrm{~ms}, 50 \mathrm{pF}$, and $20 \mathrm{M} \Omega$, respectively.

Figure Contributions: Edyta K. Bichler conducted experiments, performed statistical analysis, and prepared figure. Dieter Jaeger reviewed data and analysis.

response of the membrane potential to hyperpolarizing current steps. We determined sag responses in BGMT neurons (see Materials and Methods), and found that most but not all (Fig. 3D) recorded neurons showed a sag that was blocked by the selective $\mathrm{I}_{\mathrm{H}}$ blocker ZD7288 (Fig. $3 C)$. Comparing recordings from control and 6-OHDA lesioned mice we found that the sag amplitude of neurons that did show a sag response was larger in BGMT neurons from 6-OHDA-treated mice than in controls (Fig. $3 A, B$ ). The effect size was moderate, reaching significance for injection amplitudes of -50 and $-100 \mathrm{pA}$ with an effect size of $6.5 \mathrm{mV}(95 \% \mathrm{Cl}[0.63,12.32]) \mathrm{mV}$ for $-50 \mathrm{pA}$ and $9.0 \mathrm{mV}(95 \% \mathrm{Cl}[0.9,17.2])$ for $-100-\mathrm{pA}$ injections. Significance was missed for for -150 and -200 pA current injection steps (Fig. 3B). Since BGMT neurons show T-type calcium current dependent rebound bursts (Edgerton and Jaeger, 2014; Kim et al., 2017) similar to subthalamic neurons, the functional outcome of such an increase may be analogous to that found by Atherton et al. (2010), and decrease the propensity for rebound burst firing with strong GABAergic $B G$ input transients. 
A
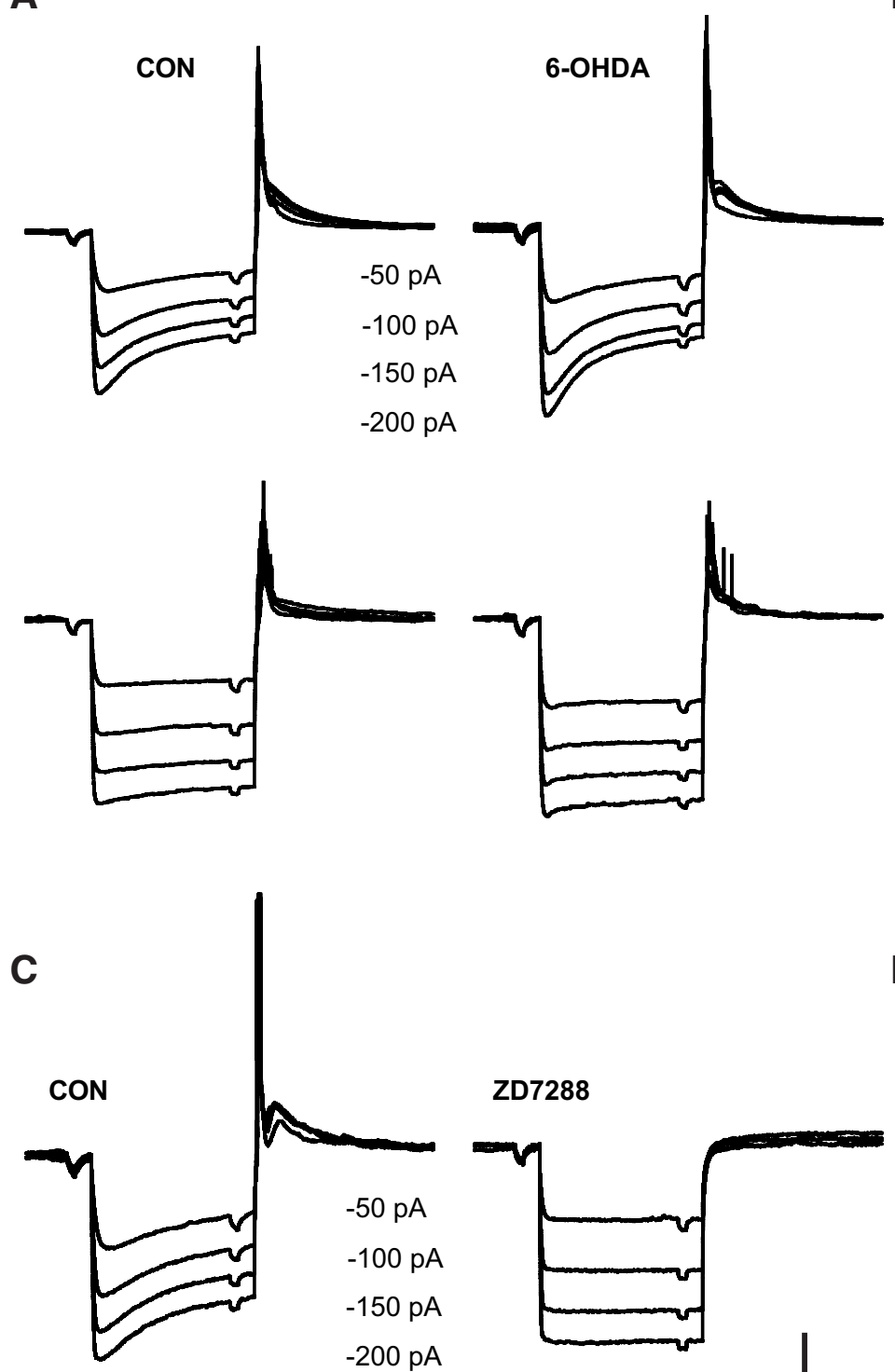

B
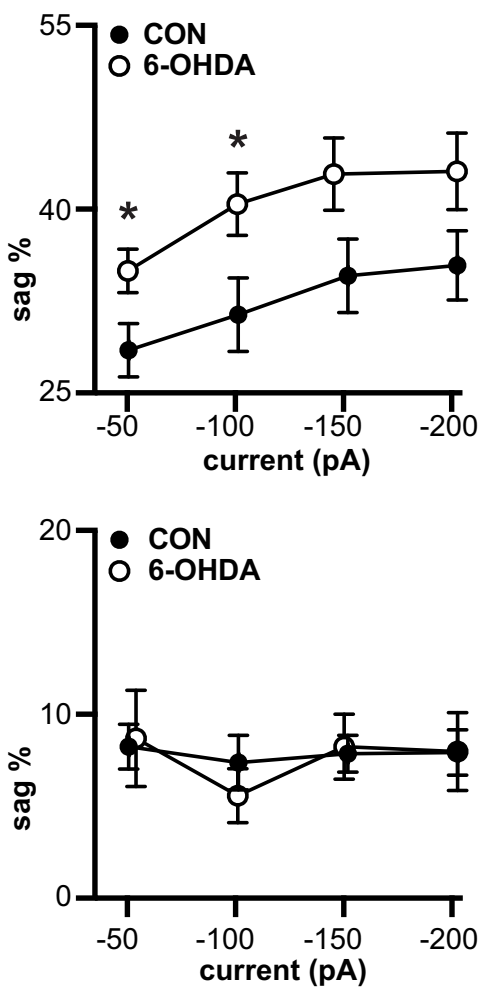

D

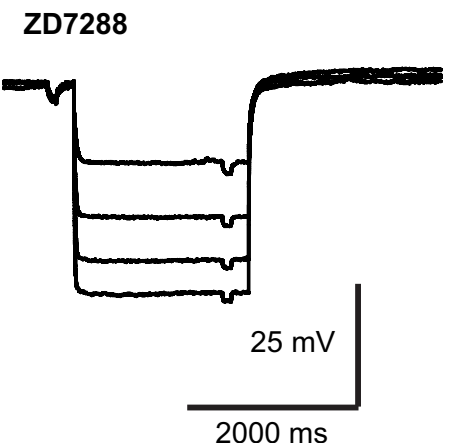

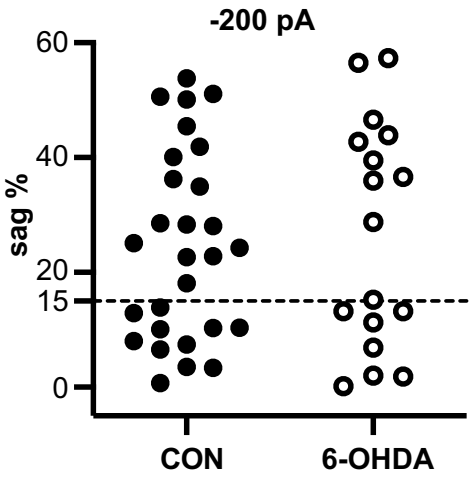

Figure 3. Sag amplitude is increased after 6-OHDA treatment. $\boldsymbol{A}$, top, Responses to hyperpolarizing current steps (ranging from -200 to $-50 \mathrm{pA}, 50-\mathrm{pA}$ increment) show the typical sag resulting from activation of $\mathrm{I}_{\mathrm{H}}$ in a majority of neurons. Some neurons, however, showed little or no sag. We defined a $15 \%$ sag amplitude (difference between peak hyperpolarization and subsequent steady state potential; see Materials and Methods) as a threshold for neurons showing a discernible sag. The panels depict grand averages of voltage responses from cells with $>15 \%$ sag responses in control mice $\left(n=16\right.$ neurons; $\left.V_{\text {Rest }}=-61.0 \pm 0.78 \mathrm{mV}\right)$ and $6-O H D A$ lesioned mice $\left(n=8\right.$ neurons; $V_{\text {Rest }}=$ $-60.9 \pm 1.01 \mathrm{mV}$ ). The average sag was more prominent $2-10$ months following 6-OHDA injection (right panel) than in controls (left panel). Bottom, Panels depicting the grand averages of responses to the same current injections in neurons with no discernible sag (control: $n=9$ neurons; $\mathrm{V}_{\text {Rest }}=-67.0 \pm 1.39 \mathrm{mV} ; 6-\mathrm{OHDA}$-treated: $n=6$ neurons; $\mathrm{V}_{\text {Rest }}=-61.6 \pm 3.5 \mathrm{mV}$ ). $\boldsymbol{B}$, top, The plots show averages of sag\% as a function of injected step size for the neurons with $>15 \%$ sag shown in panel $\boldsymbol{A}$, top. 6 -OHDA treatment resulted in an $\sim 10 \%$ increase in sag magnitude compared with controls, which was significant for -50 - and $-100-p A$ current steps, and narrowly missed significance for -150 and $-200-p A$ current steps (see Table 2). Each circle represents mean \pm SEM. Bottom, Same plots for neurons with $<15 \%$ sag amplitude (average traces shown in panel $\boldsymbol{A}$, bottom). In these neurons, the amplitude of the remaining sag was not dependent on injection step size and was not different between controls and 6-OHDA-treated mice (see Table 2). $\boldsymbol{C}$, Characteristic membrane potential responses to hyperpolarizing current steps in a representative control neuron. To block $I_{H}$ currents, external ZD7288 (specific $I_{H}$ antagonist) was added, which resulted in a complete elimination of the sag response, indicating that it was indeed due to $\mathrm{I}_{\mathrm{H}}$. $\boldsymbol{D}$, Distribution of sag amplitudes in voltage responses to 2-s -200-pA currents steps for different neurons. The dashed horizontal line designates the division into neuronal populations with no discernible sag (sag $<15 \%$ ) and clear sag-expressing cells (sag $>15 \%)$. Note that the distribution especially for the 6-OHDA-treated population is clearly bimodal.

Figure Contributions: Edyta K. Bichler conducted experiments, performed statistical analysis, and prepared figure. Dieter Jaeger reviewed data and analysis. 
CON

A
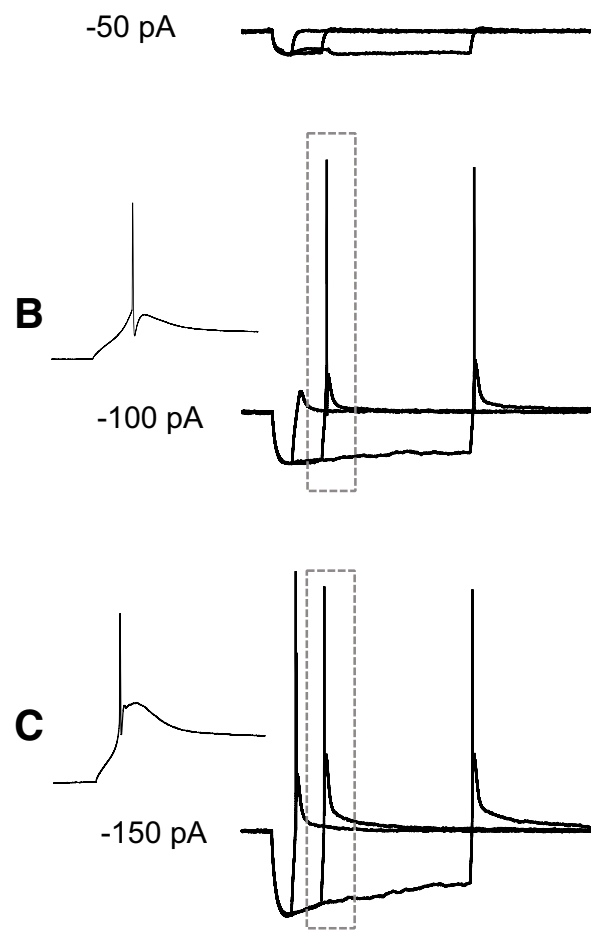

D

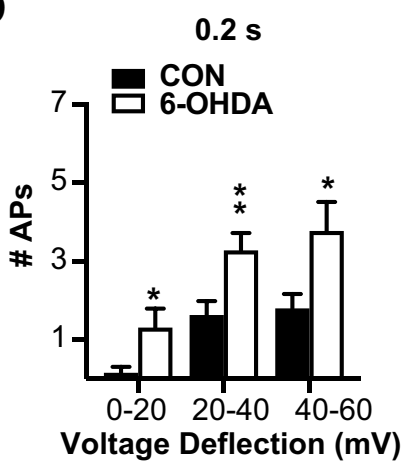

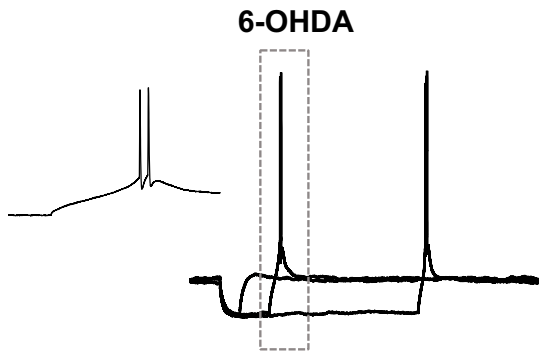
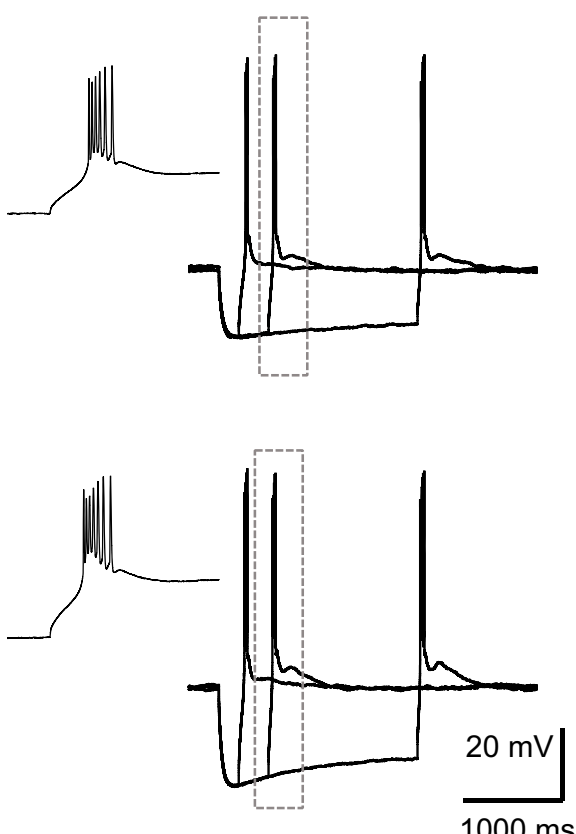

$1000 \mathrm{~ms}$
E

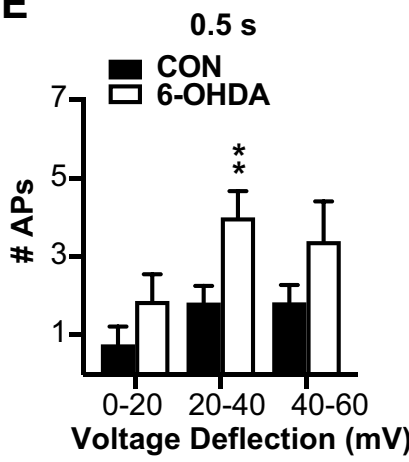

$\mathbf{F}$

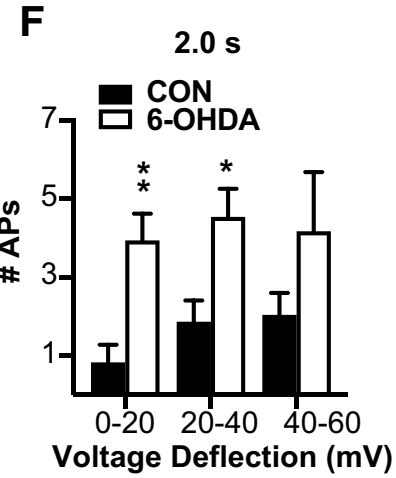

Figure 4. BGMT neurons from 6-OHDA-treated mice showed stronger rebound burst firing. A-C, Single BGMT neuron voltage traces from representative control (left) and 6-OHDA (right) mice showing responses to 50-, 100-, 150-pA hyperpolarizing stimulus steps at durations of $0.2,0.5$, or $2 \mathrm{~s}$. Dashed rectangles mark rebound bursts expanded in the inset windows to the left. $\boldsymbol{D}-\boldsymbol{F}$, Bar graph pairs represent the average number of action potentials per rebound burst \pm SEM in controls (black bars) and in 6-OHDAtreated mice (white bars). Data were sorted by the amplitude of hyperpolarization reached at the end of the step current hyperpolarizing current pulse (step amplitudes ranged from -50 to $-500 \mathrm{pA}$ at $50-\mathrm{pA}$ increments). Using this measure instead of the current injection amplitude avoids conflating rebound properties because of voltage-dependent channel de-inactivation with different levels of hyperpolarization reached because of passive $\mathrm{R}_{\text {in }}$ of differently sized neurons. Before step current injection, a tonic bias current (CON: $90.7 \pm 15.7 \mathrm{pA}$; 6-OHDA: $54.1 \pm 16.07 \mathrm{pA}$ ) was adjusted to maintain the membrane potential at a similar level for all neurons (average of $-56.52 \pm 0.6 \mathrm{mV}$ ), again to test for rebound properties under comparable voltage levels. The results show that the number of APs was increased up to $80 \%$ in neurons from 6-OHDA-treated mice, which was significant for almost all stimulus conditions (see Table 2).

Figure Contributions: Edyta K. Bichler conducted experiments, performed statistical analysis, and prepared figure. Dieter Jaeger reviewed data and analysis. 
Table 2: Statistics table

\begin{tabular}{|c|c|c|c|c|c|c|c|c|}
\hline $\begin{array}{l}\text { Fig. } \\
\#\end{array}$ & Method & Factor & $n$ & Mean \pm SEM & Medians, 5th-95th percentiles & $T, U$, or $F$ stat & $\begin{array}{l}95 \% \mathrm{Cl} \text { of } \\
\text { difference }\end{array}$ & $p$ value \\
\hline $1 B$ & Paired $t$ test, 2T & CON vs $6-\mathrm{OHDA}$ & 12,12 & $\begin{array}{l}87.85 \pm 6.57 \mathrm{vs} \\
26.19 \pm 2.14 \mathrm{AU}\end{array}$ & $\begin{array}{c}82.43 \mathrm{AU}[57.85,128.8] \text { vs } \\
26.76[11.78,36.21]\end{array}$ & $T_{(11)}=13.04$ & -72.06 to -51.25 & $<0.0001$ \\
\hline $1 C$ & Mann-Whitney, 2T & $\begin{array}{r}\text { CON vs 6-OHDA } \\
(\mathrm{F}-\mathrm{l} \text { at } 28.4 \mathrm{pA})\end{array}$ & 5,6 & $\begin{array}{l}0.0 \pm 0.0 \text { vs } \\
1.58 \pm 1.11 \mathrm{~Hz}\end{array}$ & $0[0,0]$ vs $0.5[0,7] \mathrm{Hz}$ & $U=5$ & O to 7 & 0.061 \\
\hline $1 C$ & Mann-Whitney, 2T & $\begin{array}{r}\text { CON vs 6-OHDA } \\
(\mathrm{F}-\mathrm{I} \text { at } 48.5 \mathrm{pA})\end{array}$ & 9,9 & $\begin{array}{l}0.0 \pm 0.0 \text { vs } \\
1.56 \pm 1.262 \mathrm{~Hz}\end{array}$ & $0[0,0]$ vs $0[0,11.5]$ & $U=27$ & $0-2$ & 0.206 \\
\hline $1 C$ & Mann-Whitney, 2T & $\begin{array}{l}\text { CON vs 6-OHDA } \\
(\mathrm{F}-\mathrm{I} \text { at at } 67 \mathrm{pA})\end{array}$ & 9,12 & $\begin{array}{l}0.0 \pm 0.0 \text { vs } \\
2.00 \pm 1.36 \mathrm{~Hz}\end{array}$ & $0[0,0]$ vs $0[0,15]$ & $U=36$ & $0-1$ & 0.104 \\
\hline $1 C$ & Mann-Whitney, 2T & $\begin{array}{l}\text { CON vs 6-OHDA } \\
(\mathrm{F}-\mathrm{I} \text { at } 85.6 \mathrm{pA})\end{array}$ & 13,15 & $\begin{array}{l}0.27 \pm 0.27 \mathrm{vs} \\
2.7 \pm 1.481 \mathrm{~Hz}\end{array}$ & $0[0,3.5]$ vs $0[0,19.5]$ & $U=66$ & $0-0.5$ & 0.06 \\
\hline $1 C$ & Mann-Whitney, 2T & $\begin{array}{l}\text { CON vs } 6-O H D A \\
(F-I \text { at } 105.2 \mathrm{pA})\end{array}$ & 15,16 & $\begin{array}{l}0.63 \pm 0.63 \text { vs } \\
4.81 \pm 1.89 \mathrm{~Hz}\end{array}$ & $0[0,9.5]$ vs $0[0,23.5]$ & $U=75$ & $0-7.5$ & 0.026 \\
\hline $1 C$ & Mann-Whitney, 2T & $\begin{array}{l}\text { CON vs } 6-O H D A \\
(F-I \text { at } 126.1 \mathrm{pA})\end{array}$ & 15,16 & $\begin{array}{l}1.23 \pm 0.94 \text { vs } \\
7.22 \pm 2.20 \mathrm{~Hz}\end{array}$ & $0[0,14]$ vs $3.5[0,26]$ & $U=58$ & $0-8.5$ & 0.0074 \\
\hline $1 C$ & Mann-Whitney, 2T & $\begin{array}{l}\text { CON vs } 6-\mathrm{OHDA} \\
\mathrm{F}-\mathrm{I} \text { at } 146.4 \mathrm{pA})\end{array}$ & 15,17 & $\begin{array}{l}2.30 \pm 1.31 \mathrm{vs} \\
9.12 \pm 2.48 \mathrm{~Hz}\end{array}$ & $0[0,17.5]$ vs $7[0,29.5]$ & $U=66.5$ & $0-14$ & 0.013 \\
\hline $1 C$ & Mann-Whitney, 2T & $\begin{array}{l}\text { CON vs } 6-O H D A \\
(\mathrm{~F}-\mathrm{I} \text { at } 166.5 \mathrm{pA})\end{array}$ & 16,16 & $\begin{array}{l}2.97 \pm 1.58 \text { vs } \\
10.75 \pm 2.99 \mathrm{~Hz}\end{array}$ & $0[0,21]$ vs $7.25[0,33]$ & $U=67$ & $0-10.5$ & 0.012 \\
\hline $1 C$ & Mann-Whitney, 2T & $\begin{array}{l}\text { CON vs } 6-\mathrm{OHDA} \\
(\mathrm{F}-\mathrm{I} \text { at } 187.6 \mathrm{pA})\end{array}$ & 17,16 & $\begin{array}{l}3.15 \pm 1.74 \mathrm{vs} \\
13.40 \pm 3.38 \mathrm{~Hz}\end{array}$ & $0[0,24]$ vs $9[0,40.5]$ & $U=41.5$ & $1-12$ & 0.0002 \\
\hline $1 C$ & Mann-Whitney, 2T & $\begin{array}{l}\text { CON vs } 6-O H D A \\
(\mathrm{~F}-\mathrm{I} \text { at } 207.4 \mathrm{pA})\end{array}$ & 18,15 & $\begin{array}{l}3.94 \pm 1.89 \text { vs } \\
14.97 \pm 3.46 \mathrm{~Hz}\end{array}$ & $0[0,26]$ vs $11.5[0,40]$ & $U=51.5$ & $4-14.5$ & 0.0013 \\
\hline $1 C$ & Mann-Whitney, 2T & $\begin{array}{l}\text { CON vs 6-OHDA } \\
(\mathrm{F}-\mathrm{I} \text { at } 227.3 \mathrm{pA})\end{array}$ & 18,13 & $\begin{array}{l}4.97 \pm 2.12 \text { vs } \\
13.77 \pm 2.72 \mathrm{~Hz}\end{array}$ & $0.25[0,28]$ vs $11.5[0,32.5]$ & $U=46$ & $5-15$ & 0.003 \\
\hline $1 C$ & Mann-Whitney, 2T & $\begin{array}{l}\text { CON vs } 6-O H D A \\
(\mathrm{~F}-\mathrm{I} \text { at } 247.1 \mathrm{pA})\end{array}$ & 19,12 & $\begin{array}{l}5.92 \pm 2.32 \text { vs } \\
17.29 \pm 3.068 \mathrm{~Hz}\end{array}$ & $0.5[0,31]$ vs $15.5[0,35]$ & $U=44$ & $6-18.5$ & 0.003 \\
\hline $1 C$ & Mann-Whitney, 2T & $\begin{array}{l}\text { CON vs } 6-O H D A \\
(\mathrm{~F}-\mathrm{I} \text { at } 266.9 \mathrm{pA})\end{array}$ & 18,11 & $\begin{array}{l}5.61 \pm 2.16 \text { vs } \\
18.64 \pm 3.11 \mathrm{~Hz}\end{array}$ & $1.5[0,32]$ vs $17[0,37]$ & $U=34$ & $7-19.5$ & 0.0022 \\
\hline $1 C$ & Mann-Whitney, 2T & $\begin{array}{l}\text { CON vs 6-OHDA } \\
(\mathrm{F}-\mathrm{I} \text { at } 287.2 \mathrm{pA})\end{array}$ & 18,10 & $\begin{array}{l}7.06 \pm 2.50 \mathrm{vs} \\
19.05 \pm 3.16 \mathrm{~Hz}\end{array}$ & $2.75[0,34]$ vs $18.25[0,39]$ & $U=34$ & $7-18.5$ & 0.0054 \\
\hline $1 C$ & Mann-Whitney, 2T & $\begin{array}{l}\text { CON vs } 6-O H D A \\
(\mathrm{~F}-\mathrm{I} \text { at } 306.8 \mathrm{pA})\end{array}$ & 17,10 & $\begin{array}{l}5.32 \pm 1.45 \text { vs } \\
20.15 \pm 3.22 \mathrm{~Hz}\end{array}$ & $4[0,21]$ vs $18.75[0,36.5]$ & $U=19$ & $9-21.5$ & 0.0004 \\
\hline $1 C$ & Mann-Whitney, 2T & $\begin{array}{l}\text { CON vs } 6-O H D A \\
(\mathrm{~F}-\mathrm{I} \text { at } 326.2 \mathrm{pA})\end{array}$ & 11,8 & $\begin{array}{l}5.5 \pm 1.68 \text { vs } \\
21.25 \pm 3.95 \mathrm{~Hz}\end{array}$ & $3.5[0,14]$ vs $19.75[0,38.5]$ & $U=9$ & $8.5-24$ & 0.0022 \\
\hline $1 D$ & Mann-Whitney, 2T & $\begin{array}{l}\text { CON vs 6-OHDA } \\
\text { (rheobase at } 3 \mathrm{~Hz} \text { ) }\end{array}$ & 19,17 & $\begin{array}{l}306.5 \pm 32.9 \text { vs } \\
140.3 \pm 22.62 \mathrm{pA}\end{array}$ & $\begin{array}{l}278.5 \mathrm{pA}[71.2,577.2] \text { vs } \\
119.6 \mathrm{pA}[-4.23,414.5]\end{array}$ & $U=47$ & -235.2 to -82.49 & 0.0001 \\
\hline $1 E$ & Mann-Whitney, 2T & CON vs 6-OHDA ( Rest $)$ & 46,31 & $\begin{array}{l}-64.18 \pm 0.71 \mathrm{vs} \\
-58.14 \pm 1.19 \mathrm{mV}\end{array}$ & $\begin{array}{c}-64.9 \mathrm{mV}[-70.26,-52.70] \mathrm{vs} \\
-58.5 \mathrm{mV}[-72.0,-49.6]\end{array}$ & $U=310.5$ & $3.6-9.8$ & $<0.0001$ \\
\hline $1 F$ & Unpaired $t$ test, 2T & $\mathrm{CON}$ vs $6-\mathrm{OHDA}\left(\mathrm{V}_{T}\right)$ & 18,17 & $\begin{array}{l}-32.16 \pm 1.18 \mathrm{vs} \\
-36.31 \pm 1.00 \mathrm{mV}\end{array}$ & $\begin{array}{c}-32.95 \mathrm{mV}[-39.03,-17.5] \mathrm{vs} \\
-36.4 \mathrm{mV}[-43.7,-27.8]\end{array}$ & $T_{(33)}=2.672$ & -7.32 to -0.991 & 0.0116 \\
\hline $2 A$ & Unpaired $t$ test, 2T & CON vs $6-\mathrm{OHDA}\left(\mathrm{T}_{a u}\right)$ & 12,13 & $\begin{array}{l}20.7 \pm 2.97 \mathrm{vs} \\
21.04 \pm 3.66 \mathrm{~ms}\end{array}$ & $\begin{array}{r}22.83 \mathrm{~ms}[5.4,36.65] \mathrm{vs} \\
13.8 \mathrm{~ms}[4.85,47.25]\end{array}$ & $T_{(23)}=0.07198$ & $-9.50-10.19$ & 0.9432 \\
\hline $2 B$ & Unpaired $t$ test, 2T & $\begin{array}{r}\text { CON vs 6-OHDA } \\
\text { (capacitance) }\end{array}$ & 12,13 & $\begin{array}{r}112.6 \pm 17.42 \mathrm{vs} \\
117.0 \pm 26.6 \mathrm{pF}\end{array}$ & $\begin{array}{c}112 \mathrm{pF}[16.8,259.1] \text { vs } \\
80.2 \mathrm{pF}[8.95,277]\end{array}$ & $T_{(23)}=0.1341$ & $-62.63-71.31$ & 0.8945 \\
\hline $2 C$ & Mann-Whitney, 2T & $\mathrm{CON}$ vs $6-\mathrm{OHDA}\left(\mathrm{R}_{\text {in }}\right)$ & 17,13 & $\begin{array}{l}192.9 \pm 19.24 \text { vs } \\
229.5 \pm 26.34 \mathrm{M} \Omega\end{array}$ & $\begin{array}{r}166.0 \mathrm{M} \Omega[98.54,385.0] \mathrm{vs} \\
212.0 \mathrm{M} \Omega[125.0,476.0]\end{array}$ & $U=79$ & $-27-94$ & 0.1940 \\
\hline $3 B$, top & Mixed effect, UF & $\begin{array}{l}\text { CON vs } 6-O H D A \\
\quad(\mathrm{Sag} \% \text { at }-50 \mathrm{pA})\end{array}$ & 16,8 & $\begin{array}{r}28.50 \pm 2.18 \% \text { vs } \\
34.97 \pm 1.78 \%\end{array}$ & & $T_{(21.3)}=2.3$ & $0.626-12.32$ & 0.0316 \\
\hline $3 B$, top & Mixed effect, UF & $\begin{array}{l}\text { CON vs 6-OHDA } \\
\qquad(\mathrm{Sag} \% \text { at }-100 \mathrm{pA})\end{array}$ & 17,9 & $\begin{array}{r}31.38 \pm 3.00 \% \text { vs } \\
40.42 \pm 2.55 \%\end{array}$ & & $T_{(23.2)}=2.296$ & $0.901-17.19$ & 0.0310 \\
\hline $3 B$, top & Mixed effect, UF & $\begin{array}{l}\text { CON vs 6-OHDA } \\
\qquad(\mathrm{Sag} \% \text { at }-150 \mathrm{pA})\end{array}$ & 16,8 & $\begin{array}{r}34.57 \pm 3.0 \% \text { vs } \\
42.86 \pm 2.95 \%\end{array}$ & & $T_{(19.3)}=1.969$ & $-0.512-17.1$ & 0.0634 \\
\hline $3 B$, top & Mixed effect, UF & $\begin{array}{l}\text { CON vs 6-OHDA } \\
\qquad(\mathrm{Sag} \% \text { at }-200 \mathrm{pA})\end{array}$ & 17,9 & $\begin{array}{c}35.42 \pm 2.84 \% \text { vs } \\
43.1 \pm 3.13 \%\end{array}$ & & $T_{(19.9)}=1.817$ & -1.14 to -16.5 & 0.0843 \\
\hline $3 B$, bottom & Mixed effect, UF & $\begin{array}{l}\text { CON vs } 6-\mathrm{OHDA} \text { (Sag\% } \\
\text { at }-50 \mathrm{pA})\end{array}$ & 10,7 & $\begin{array}{r}8.24 \pm 1.21 \% \text { vs } \\
8.69 \pm 2.63 \%\end{array}$ & & $T_{(8.5)}=0.1537$ & $-6.15-7.04$ & 0.8814 \\
\hline $3 B$, bottom & Mixed effect, UF & $\begin{array}{l}\text { CON vs } 6-\mathrm{OHDA}(\mathrm{Sag} \% \\
\text { at }-100 \mathrm{pA})\end{array}$ & 11,7 & $\begin{array}{r}7.37 \pm 1.48 \% \text { vs } \\
5.58 \pm 1.48 \%\end{array}$ & & $T_{(15)}=0.856$ & $-6.25-2.67$ & 0.4055 \\
\hline $3 B$, bottom & Mixed effect, UF & $\begin{array}{l}\text { CON vs } 6-O H D A \text { (Sag } \% \\
\text { at }-150 \mathrm{pA})\end{array}$ & 10,7 & $\begin{array}{r}7.85 \pm 1.01 \% \text { vs } \\
8.24 \pm 1.76 \% \\
\text { (Continued) }\end{array}$ & & $T_{(9.9)}=0.1915$ & $-4.14-4.92$ & 0.8520 \\
\hline
\end{tabular}


Table 2: Continued

\begin{tabular}{|c|c|c|c|c|c|c|c|c|}
\hline $\begin{array}{l}\text { Fig. } \\
\#\end{array}$ & Method & Factor & $n$ & Mean \pm SEM & Medians, 5th-95th percentiles & $T, U$, or $F$ stat & $\begin{array}{l}95 \% \mathrm{Cl} \text { of } \\
\text { difference }\end{array}$ & $p$ value \\
\hline $3 B$, bottom & Mixed effect, UF & $\begin{array}{l}\text { CON vs } 6-\mathrm{OHDA} \text { (Sag\% at } \\
-200 \mathrm{pA})\end{array}$ & 11,8 & $\begin{array}{r}7.93 \pm 1.25 \% \text { vs } \\
7.98 \pm 2.13 \%\end{array}$ & & $T_{(11.7)}=0.01873$ & -5.34 to -5.43 & 0.9854 \\
\hline $3 D$ & Unpaired $t$ test, 2T & CON vs 6-OHDA & 28,17 & $\begin{array}{r}24.62 \pm 3.13 \% \text { vs } \\
26.57 \pm 4.77 \%\end{array}$ & $\begin{array}{r}23.54 \%[1.9,52.56] \text { vs } \\
28.76 \%[0.17,57.3]\end{array}$ & $T_{(43)}=0.3569$ & $-9.08-12.98$ & 0.7229 \\
\hline $4 D$ & Mann-Whitney, 2T & $\begin{array}{l}\text { CON vs 6-OHDA } \\
\qquad(\# A P \text { at } 0-20 \mathrm{mV})\end{array}$ & 13,13 & $\begin{array}{c}0.154 \pm 0.154 \mathrm{vs} \\
1.31 \pm 0.486\end{array}$ & $0[0,2]$ vs $0[0,5]$ & $U=51$ & $0-2$ & 0.044 \\
\hline $4 D$ & Mann-Whitney, 2T & $\begin{array}{l}\text { CON vs } 6-O H D A \\
(\# A P \text { at } 20-40 \mathrm{mV})\end{array}$ & 15,17 & $\begin{array}{r}1.63 \pm 0.359 \text { vs } \\
3.28 \pm 0.445\end{array}$ & $1.25[0,5]$ vs $3.5[0,6]$ & $U=57$ & $0.5-3$ & 0.0065 \\
\hline $4 D$ & Mann-Whitney, 2T & $\begin{array}{l}\text { CON vs 6-OHDA } \\
\qquad(\# A P \text { at } 40-60 \mathrm{mV})\end{array}$ & 14,9 & $\begin{array}{r}1.80 \pm 0.367 \text { vs } \\
3.78 \pm 0.741\end{array}$ & $1.167[0,5]$ vs $4.0[0,7]$ & $U=27.5$ & $5-4$ & 0.0226 \\
\hline $4 E$ & Mann-Whitney, 2T & $\begin{array}{l}\text { CON vs } 6-O H D A \\
\qquad(\# A P \text { at } 0-20 \mathrm{mV})\end{array}$ & 9,9 & $\begin{array}{r}0.76 \pm 0.459 \text { vs } \\
1.87 \pm 0.683\end{array}$ & $0[0,4]$ vs $1[0,5]$ & $U=26$ & $0-4$ & 0.2018 \\
\hline $4 E$ & Mann-Whitney, 2T & $\begin{array}{l}\text { CON vs 6-OHDA } \\
\qquad(\# A P \text { at } 20-40 \mathrm{mV})\end{array}$ & 12,12 & $\begin{array}{r}1.83 \pm 0.444 \text { vs } \\
4.01 \pm 0.673\end{array}$ & $1[0.666,5]$ vs $4.7[0.5,7.75]$ & $U=28.5$ & $0.4-4.5$ & 0.0099 \\
\hline $4 E$ & Mann-Whitney, 2T & $\begin{array}{l}\text { CON vs 6-OHDA } \\
\qquad(\# A P \text { at } 40-60 \mathrm{mV})\end{array}$ & 10,6 & $\begin{array}{c}1.83 \pm 0.444 \mathrm{vs} \\
3.4 \pm 1.013\end{array}$ & $1[1,5.333]$ vs $3[1,7]$ & $U=18$ & $0-4.4$ & 0.1776 \\
\hline $4 F$ & Mann-Whitney, 2T & $\begin{array}{l}\text { CON vs 6-OHDA } \\
\qquad(\# A P \text { at } 0-20 \mathrm{mV})\end{array}$ & 8,12 & $\begin{array}{c}0.82 \pm 0.4533 \text { vs } \\
3.94 \pm 0.683\end{array}$ & $0.1665[0,3.5]$ vs $5[0,6.750]$ & $U=12.5$ & $1-5.25$ & 0.0042 \\
\hline $4 F$ & Mann-Whitney, 2T & $\begin{array}{l}\text { CON vs 6-OHDA } \\
\qquad(\# A P \text { at } 20-40 \mathrm{mV})\end{array}$ & 12,12 & $\begin{array}{r}1.87 \pm 0.54 \text { vs } \\
4.54 \pm 0.716\end{array}$ & $1[0,6]$ vs $4.9[0.6,8.0]$ & $U=30$ & $0.5-5$ & 0.0132 \\
\hline $4 F$ & Mann-Whitney, 2T & $\begin{array}{l}\text { CON vs 6-OHDA } \\
\qquad(\# A P \text { at } 40-60 \mathrm{mV})\end{array}$ & 9,5 & $\begin{array}{c}2.04 \pm 0.562 \text { vs } \\
4.17 \pm 1.51\end{array}$ & $1[1,6]$ vs $4.2[1,9]$ & $U=15$ & $-1-5.67$ & 0.311 \\
\hline $5 D$ & Paired $t$ test, 2T & $\begin{array}{l}\text { CON vs XE991 } \\
\text { rheobase at } 3 \mathrm{~Hz}\end{array}$ & 8,8 & $\begin{array}{l}295.0 \pm 41.19 \mathrm{vs} \\
225.2 \pm 38.59 \mathrm{pA}\end{array}$ & $\begin{array}{c}317.7 \mathrm{pA}[137.7,440.7] \mathrm{vs} \\
202.8 \mathrm{pA}[90.6,379.2]\end{array}$ & $T_{(7)}=2.81$ & -128.5 to -11.1 & 0.0261 \\
\hline $5 E$ & Paired $t$ test, $2 \mathrm{~T}$ & $\begin{array}{l}\text { CON vs XE991 } \\
\text { rheobase at } 10 \mathrm{~Hz}\end{array}$ & 8,8 & $\begin{array}{l}325.9 \pm 43.4 \mathrm{vs} \\
263.8 \pm 40.9 \mathrm{pA}\end{array}$ & $\begin{array}{r}354.6 \mathrm{pA}[167.7,454.1] \mathrm{vs} \\
247.7 \mathrm{pA}[114.7,417.8]\end{array}$ & $T_{(7)}=2.591$ & -118.7 to -5.42 & 0.0359 \\
\hline $5 F$ & Paired $t$ test, 2T & CON vs XE991 $\left(V_{T}\right)$ & 8,8 & $\begin{array}{l}-32.89 \pm 1.19 \mathrm{vs} \\
-35.31 \pm 1.28 \mathrm{mV}\end{array}$ & $\begin{array}{l}-32.78 \mathrm{mV}[-39.09,-27.6] \mathrm{vs} \\
-34.37 \mathrm{mV}[-43.15,-32.24]\end{array}$ & $T_{(7)}=3.841$ & -3.90 to -0.927 & 0.0064 \\
\hline $5 H$ & Wilcoxon, 2T & $\begin{array}{l}\text { 6-OHDA vs XE991 } \\
\text { rheobase at } 3 \mathrm{~Hz}\end{array}$ & 10,10 & $\begin{array}{l}124.7 \pm 38.56 \mathrm{vs} \\
113.5 \pm 37.76 \mathrm{pA}\end{array}$ & $\begin{array}{c}87.06 \mathrm{pA}[-6.46,385.5] \mathrm{vs} \\
80 \mathrm{pA}[-16.6,373]\end{array}$ & $W=-35.00$ & $-17.41-3.96$ & 0.0840 \\
\hline 51 & Paired $t$ test, 2T & $\begin{array}{l}\text { 6-OHDA vs XE991 } \\
\quad \text { rheobase at } 10 \mathrm{~Hz}\end{array}$ & 8,8 & $\begin{array}{l}100 \pm 25.2 \text { vs } \\
92 \pm 21.9 p A\end{array}$ & $\begin{array}{l}102.4 \mathrm{pA}[2.321,193.2] \mathrm{vs} \\
103.2 \mathrm{pA}[-5.874,166.2]\end{array}$ & $T_{(7)}=1.575$ & $-20.6-4.13$ & 0.1593 \\
\hline $5 \mathrm{~J}$ & Paired $t$ test, 2T & $6-0$ HDA vs XE991 $\left(V_{T}\right)$ & 10,10 & $\begin{array}{l}-38.0 \pm 1.4 \mathrm{vs} \\
-38.1 \pm 1.3 \mathrm{mV}\end{array}$ & $\begin{array}{l}-37.8 \mathrm{mV}[-48,-31.9] \text { vs } \\
-37.8 \mathrm{mV}[-45.2,-33.7]\end{array}$ & $T_{(9)}=0.1454$ & $-1.54-1.35$ & 0.8876 \\
\hline
\end{tabular}

2T, two-tailed; UF, uncorrected Fisher's LSD (post hoc correction).

\section{T-type Ca channel dependent rebound burst firing is increased in neurons from 6-OHDA-treated mice}

We next directly addressed the question whether Ttype calcium current mediated rebound bursts were affected in BGMT neurons in 6-OHDA lesioned mice. To elicit rebound bursts, we injected negative current steps for $0.2,0.5$, or $2 \mathrm{~s}$ with amplitudes of between -50 and $-500 \mathrm{pA}$ (Fig. 4). As expected from T-type current-mediated rebound bursts in thalamic neurons and shown in previous studies (Edgerton and Jaeger, 2014; Kim et al., 2017), these hyperpolarizing steps elicited strong two to eight action potential bursts riding on a broader peak of depolarization caused by $\mathrm{I}_{\mathrm{T}}$ (Llinás and Jahnsen, 1982). As expected, longer and stronger hyperpolarizing steps elicited stronger rebound bursts as measured by the number of action potentials in the rebound (Fig. $4 E, F$ ). In contrast to an attenuation of rebounds that might be expected from an increase in $I_{H}$ (Atherton et al., 2010), however, we found a significant increase in the number of rebound burst spikes in BGMT neurons from 6-OHDA lesioned mice for all stimulus conditions except the smallest and shortest step depolarization (Fig. 4D-F). For example, for 0.5 -s stimuli inducing $20-40 \mathrm{mV}$ hyper- polarization, the effect size was 3.7 more rebound burst spikes in 6-OHDA lesioned mice with a $95 \% \mathrm{Cl}$ of $[0.4,4.5]$. See Table 2 for effect sizes and $p$ values of all stimulus combinations. A typical example for a BGMT neuron from a control and a 6-OHDA lesioned mouse is shown in Figure $4 A-C$.

\section{The increase in tonic spiking frequency after 6-OHDA treatment is at least partly explained via a reduction of $\mathbf{I}_{\mathbf{M}} \mathbf{K}^{+}$conductance in BGMT neurons}

A previous study in VB thalamocortical neurons showed that the $I_{M}$ carried by Kv7.2 and Kv7.3 channels can lead to a decrease in $V_{\text {Rest }}$, a decrease in firing frequency with depolarizing current steps, and a decrease in burst spikes at the offset of hyperpolarizing steps (Cerina et al., 2015). Since these observations fit the profile of our observed changes after 6-OHDA treatment quite well, we wondered whether they are associated with a decrease in $I_{M}$ current. We used the specific KV7 blocker XE-991 (Greene et al., 2017) to determine whether blocking KV7 current has a differential effect on BGMT neurons from control or 6OHDA-treated mice. We found indeed that application of 

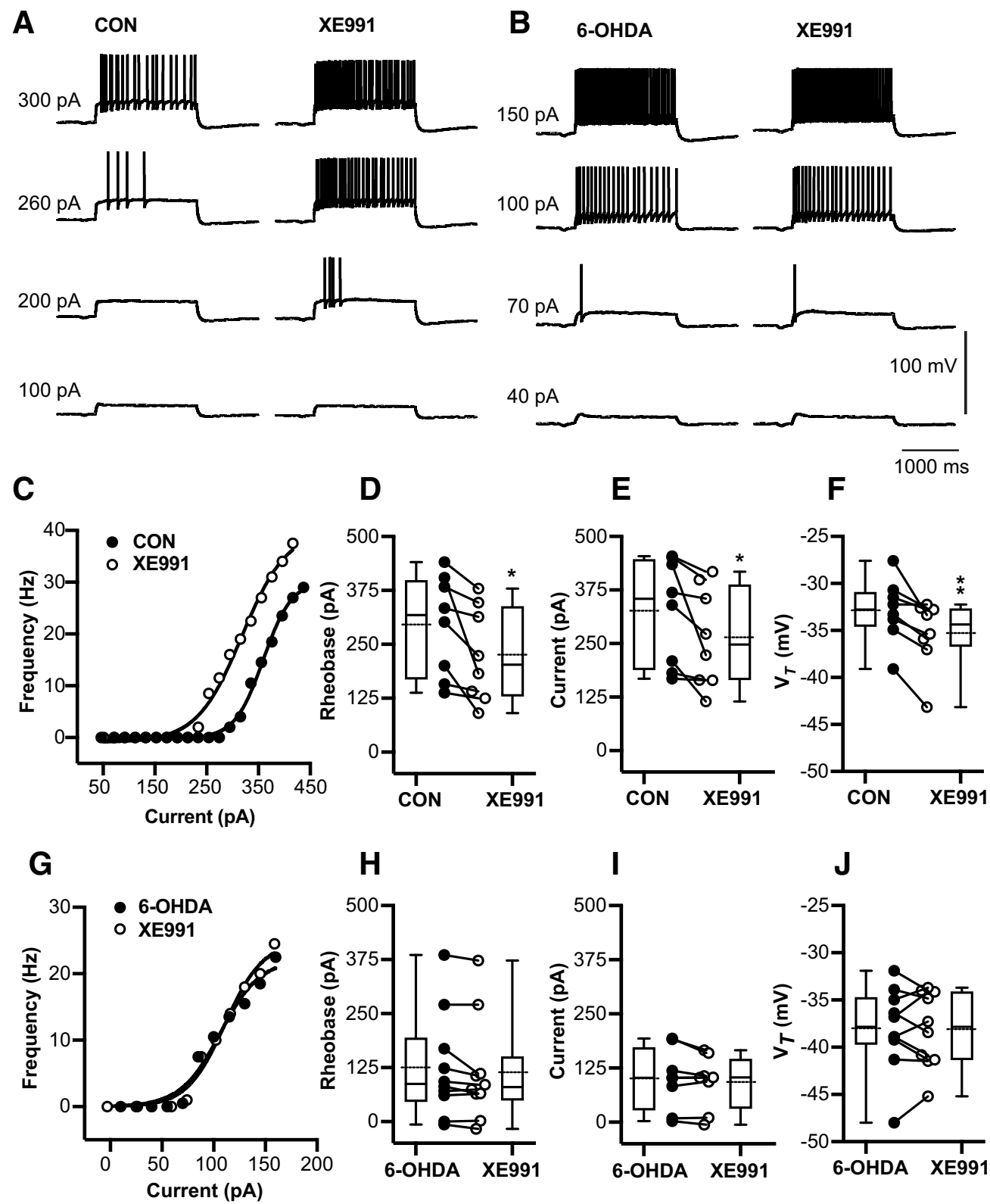

Figure 5. 6-OHDA application enhances tonic spike firing in BGMT neurons via a reduction of $\mathrm{I}_{\mathrm{M}} \mathrm{K}^{+}$conductance. $\boldsymbol{A}$, Voltage responses to increasing depolarizing step current injections $(100,200,260,300 \mathrm{pA})$ for a representative neuron of control mouse before (left panel) and after $10 \mathrm{~min}$ of adding 10-20 $\mu \mathrm{M}$ XE-991 to the bath ACSF (right panel). To block ionotropic glutamatergic and GABAergic synaptic inputs, DNQX (AMPA/kainate receptors antagonist, $10 \mu \mathrm{M}$ ), D-AP5 (NMDA receptor antagonists, $50 \mu \mathrm{M}$ ), and gabazine (GABA-A antagonist, $10 \mu \mathrm{M}$ ) were present in the ACSF throughout. $\boldsymbol{B}$, Voltage responses to increasing pulse current injections (at amplitude 40,70,100,150 pA) of respresenative neuron from 6-OHDA-treated mouse before (left panel) and after (right panel) 10-min application of XE-991. C , The F-I curve of a representative neuron from a control mouse is shown before and after 10-20 min bath exposure to XE-991 (10-20 $\mu \mathrm{M})$. The lift shift following XE991 exposure suggests $I_{M}$ inhibition induced hyperexcitability. $\boldsymbol{D}$, For each individual neuron, a Boltzmann sigmoidal fit was done for the F-I curve and the intercept at 3-Hz firing was determined as rheobase (see Materials and Methods). Neurons after exposure to XE-991 showed significant reduction in the rheobase compared with control ACSF (CON: 295.0 $\pm 41.19 \mathrm{pA}$; CON + XE-991: $225.2 \pm 38.59 \mathrm{pA}, n=8$; paired $t$ test, $p=0.026)$. Baseline

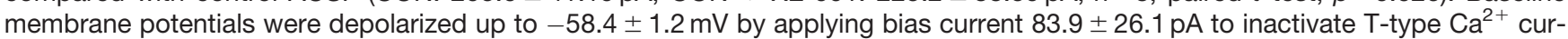
rents and prevent burst firing. $\boldsymbol{E}$, Based on Boltzmann sigmoidal fit for the $\mathrm{F}-\mathrm{I}$ curve, the intercept at $10-\mathrm{Hz}$ firing was determined as current at $10 \mathrm{~Hz}$ (see Materials and Methods). Neurons showed a significant reduction in the current required to drive 10-Hz firing after XE-991 application (CON: $325.9 \pm 43.4 \mathrm{pA}$; CON + XE-991: $263.8 \pm 40.94 \mathrm{pA}, n=8$; paired $t$ test, $p=0.0359$ ). $\boldsymbol{F}$, Average $\mathrm{V}_{T}$ significantly decreased in the presence of XE-991 (CON: $-32.89 \pm 1.18 \mathrm{mV}$; CON + XE-991: $-35.3 \pm 1.28 \mathrm{mV}$; paired $t$ test, $p=0.0064)$. G-J, XE-991 did not generate further changes in firing frequency of neurons from 6-OHDA-treated mice (6-OHDA vs 6OHDA + XE-991) 1-7.1 months post lesion (mean \pm SEM: $4.0 \pm 1.0$ months). G, Example of firing in single 6-OHDA neuron. Neither tonic rheobase (6-OHDA: 87.1 pA [-6.5,385.5]; 6-OHDA + XE-991: 80.0 pA [-16.6,372.7], $n=10$; Wilcoxon test, $p=0.084$ ), current at $10-\mathrm{Hz}$ 6-OHDA: $100.3 \pm 25.18 \mathrm{pA} ; 6-\mathrm{OHDA}+\mathrm{XE}-991$ : $92.04 \pm 21.87 \mathrm{pA}, n=8$; paired $t$ test, $p=0.159)$, nor $V_{T}(6-O H D A$ : 


\section{continued}

$-38.03 \pm 1.4 \mathrm{mV}$; $6-O H D A+X E-991:-38.12 \pm 1.3 \mathrm{mV}, n=10$; paired $t$ test, $p=0.88$ ) showed changes in the presence of XE-991. Box and whisker plots represent medians, quartiles, and 5th-95th percentiles. Individual neurons are shown as line graphs between the whisker plots.

Figure Contributions: Edyta K. Bichler conducted experiments, performed statistical analysis, and prepared figure. Dieter Jaeger reviewed data and analysis.

10-20 $\mu \mathrm{M}$ XE-991 resulted in a marked increase in tonic firing frequency in response to depolarizing steps in neurons from control mice (example neuron in Fig. $5 \mathrm{C}$ ), indicating the presence of KV7 channels and a role in dampening tonic spike frequencies. Across all neurons from control mice, XE-991 application resulted in a reduced rheobase ( $n=8$ neurons, $p=0.026)$. The effect size was a 70-pA lower current injection to evoke $3-\mathrm{Hz}$ firing than before XE-991 application (Fig. 5D), with a $95 \% \mathrm{Cl}$ of $[-128.5,-11.1]$, and a 62.1-pA lower current to evoke 10$\mathrm{Hz}$ firing (Fig. $5 E$ ) with a $95 \% \mathrm{Cl}$ of $[-118.7,-5.42]$. In addition, the voltage at spike threshold $\mathrm{V}_{T}$ ) was also significantly lower after XE-991application $(p=0.0064$; Fig. $5 F)$, with an effect size of $-2.4 \mathrm{mV}$ and a $95 \% \mathrm{Cl}$ of $[-3.9,-0.93]$. In contrast, none of these effects were observed in neurons from 6-OHDA-treated mice ( $n=10$ neurons; Fig. $5 H-J)$, The lack of effect of XE-991 indicates a lack of functional $I_{M}$ current in these neurons. Together, these results indicate that a reduction in $I_{M}$ current can likely account for the majority of changes seen in intrinsic excitability in BGMT neurons following 6-OHDA treatment.

\section{Analysis of $I_{M}$ current effects in a biophysically realistic neuron model}

We simulated the current step protocols as used in our experimental approach. Reducing or blocking the $\mathrm{I}_{\mathrm{M}}$ current resulted in increased tonic firing as well as a lower rheobase (Fig. $6 A, B$ ). Full blockade of the $\mathrm{I}_{\mathrm{M}}$ conductance also resulted in an increase in rebound burst spikes following hyperpolarizing current steps, while a reduction to $50 \%$ was not sufficient to cause this effect (Fig. 6C,D). Interestingly, a full blockade of $I_{M}$ could also increase the sag amplitude when we simulated the hyperpolarizing steps used in our study (Fig. $6 E, F$ ); however, this effect by itself was not large enough to explain the magnitude of differences seen between control and 6-OHDA lesioned mice in our slice recordings. Therefore, an additional increase in $\mathrm{I}_{\mathrm{H}}$ current amplitude is likely to be required to match our experimental findings (Fig. $6 F$, no $I_{M}, 300 \% I_{H}$ ).

\section{Discussion}

Changes in cellular properties have been observed in multiple key structures related to Parkinsonian motor dysfunction beyond primary striatal dysfunction directly elicited by dopamine depletion. Notably, in an elegant set of studies the Bevan lab showed that in the STN 6-OHDA treatment in rodents leads to changes in synaptic as well as intrinsic properties (Wilson and Bevan, 2011; Fan et al., 2012; Chu et al., 2015, 2017; Mclver et al., 2019; Kovaleski et al., 2020). A prominent synaptic change in STN is given by homeostatic upregulation of the GPe
GABAergic input conductance through a mechanism caused by cortical NMDA input overactivation (Chu et al., 2015), which contributes to the emergence of pathologically correlated STN-GPe activity patterns (Magill et al., 2001; Walters et al., 2007; Mallet et al., 2008). In addition, NMDA overactivation after 6-OHDA depletion results in a downregulation of STN autonomous spiking because of an increase in $\mathrm{K}_{\text {ATP }}$ channel activity (Mclver et al., 2019). These studies demonstrate that pathologic input levels and input patterns can lead to homeostatic changes in cellular properties without the need for direct dopamine modulation. The BGMT in rodents is very sparsely if at all innervated by dopaminergic fibers (García-Cabezas et al., 2009), making direct dopaminergic effects unlikely. However, BG output from SNr has been shown to be more synchronized and bursty following 6-OHDA treatment in rodents (Murer et al., 1997; Avila et al., 2010; Brazhnik et al., 2014; Lobb, 2014; Lobb and Jaeger, 2015). Such changed input patterns are likely to trigger homeostatic plasticity mechanisms in BGMT that can then further change the integrative properties of the thalamocortical pathway neurons and may lead to maladaptive activity patterns contributing to Parkinsonian motor dysfunction.

We addressed the question of BGMT changes in cellular properties after unilateral 6-OHDA treatment in mice that had undergone a minimum of one month of dopamine depletion allowing homeostatic compensation mechanisms to take place. We found a pronounced increase in excitability because of a decrease in M-type potassium current. This outcome will result in increased BGMT spiking activity that would be compensatory to increased levels of inhibitory BG input. However, the concomitant increase of T-type calcium channel elicited postinhibitory rebound LTS bursting would also be likely to lead to an increased burstiness of BGMT output, particularly in the presence of synchronized inhibitory input bursts originating from the SNr. Increased motor thalamic LTS bursting has been found in MPTP-treated primates (Magnin et al., 2000; Devergnas et al., 2016) and in the dopamine deficient SPR-KO mouse model (Kim et al., 2017). While assessment of VM bursting in awake rodents is yet lacking, a recent study shows increased bursting following 6OHDA treatment recorded under urethane anesthesia (Di Giovanni et al., 2020). Interestingly, in this study, an acute dopamine depletion led to a decrease in BGMT firing rate and increase in thalamic GABA transmission, whereas the chronic 6-OHDA depleted state resulted not in a firing rate change, but in increased bursting, supporting the notion of an intervening homeostatic mechanism as dopamine depletion persists. Another recent study of the ventrolateral (VL) thalamus that receives some GPi BG input (Cebrian et al., 2005), showed increased rebound activity 
A
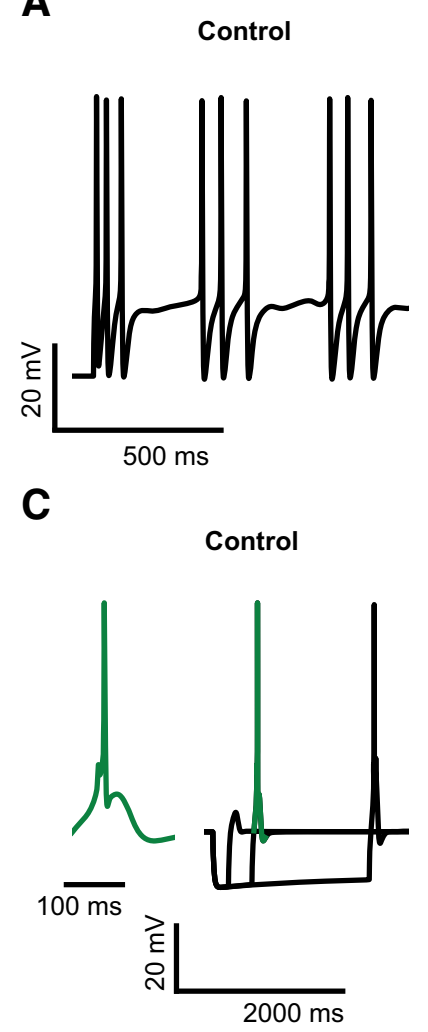

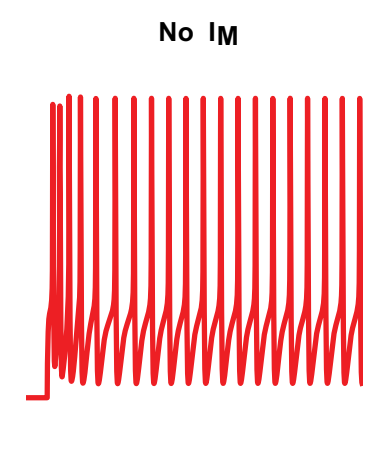

No IM

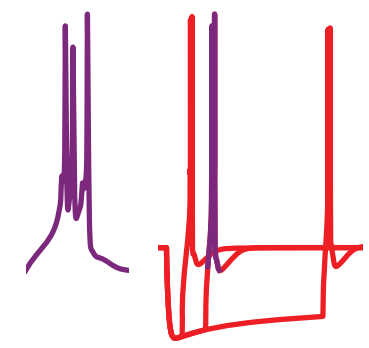

B

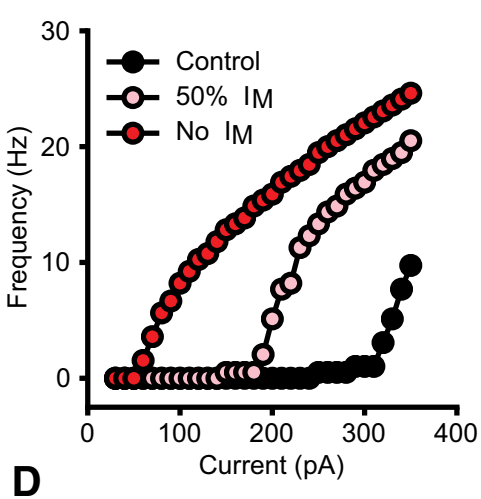

D

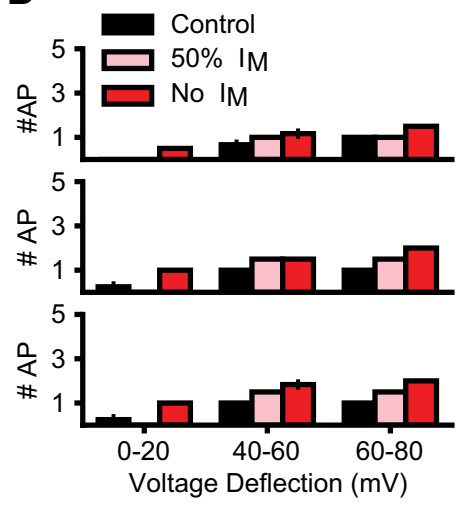

$\mathbf{F}$

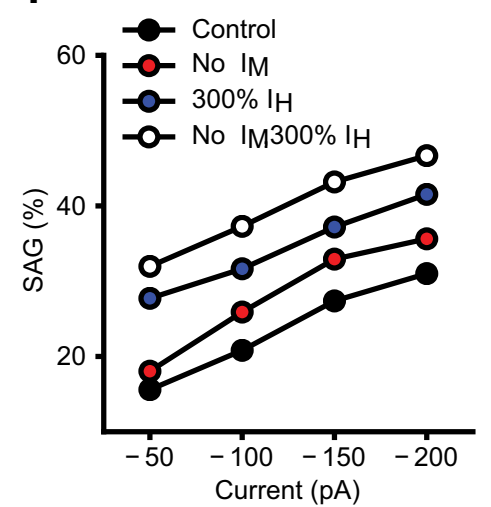

Figure 6. $\boldsymbol{A}$, Simulated firing of BGMT thalamocortical neuron to somatic current injection ( $350 \mathrm{pA}$; 2 s of duration) for control (black trace) and after $I_{M}$ blockade (red trace). For both, membrane potential was held at $\sim-64 \mathrm{mV}$ to inactivate $T$ calcium channels and evoke tonic firing on depolarization. $I_{M}$ blockade increases the model firing rate (compare black and red traces). $\boldsymbol{B}$, Injected currentfiring rate relationship of the model ( $F-I$ plot) for control (black), after $50 \%$ reduction (pink) and full blockade (red) of $I_{M}$ current, with current intensities of 30-360 pA. I reduction and blockade shifts the F-I curve leftward, resulting in a decrease in spike threshold as well as an increase in firing rate. $\boldsymbol{C}$, Rebound bursts in the model neuron evoked by hyperpolarizing current steps $(-100 \mathrm{pA})$ of different durations $(200,500,2000 \mathrm{~ms})$, for control (black) and after $I_{M}$ blockade (red). Insets show an expanded wave forms of a burst (green, purple). Membrane potential was held at $\sim-71 \mathrm{mV}$. $\mathrm{I}_{\mathrm{M}}$ reduction increases the rebound burst duration, i.e., spike count (compare green and purple wave form). $\boldsymbol{D}$, Spike count in rebound bursting as in $\boldsymbol{C}$, evoked by current steps of $200 \mathrm{~ms}$ (top), $500 \mathrm{~ms}$ (center), and $2000 \mathrm{~ms}$ (bottom), for control (black), after $50 \%$ reduction (pink) and full blockade (red) of $\mathrm{I}_{\mathrm{M}}$ conductance. $\boldsymbol{E}$, Sag generated in response to hyperpolarizing current pulses of increasing intensities (50-200 pA; no holding current) for control (black), after $I_{M}$ blockade (red), and $200 \%$ increase of $I_{H}$ (blue). $\boldsymbol{F}$, Sag amplitude versus hyperpolarizing current intensity for control (black), after $I_{M}$ blockade, $200 \%$ increase of $I_{H}$ (blue), or combination of both changes (white). $I_{M}$ blockade makes a small increase in sag amplitudes (compare red and black), while $I_{H}$ increase brings the amplitudes to similar levels as observed in 6-OHDA-lesioned condition (compare blue, white, and black), combination of both changes allows to replicate the increase in the sag observed experimentally (compare white and black).

Figure Contributions: Francesco Cavarretta conducted simulations, performed analysis, and prepared figure. Dieter Jaeger reviewed data and analysis. 
in mice after optonetic GPi terminal activation (Kim et al., 2017).

The M-type current (carried by KCNQ channels, more recently renamed as Kv7 channels) has been previously shown to be present in thalamocortical neurons in sensory thalamic neurons (Kasten et al., 2007), where a block by XE-991 moderately enhanced firing rate and lowered rheobase. More recently, both Kv7.2 and Kv7.3 were found abundantly expressed in the VB thalamus, and the number of LTS spikes following hyperpolarization increased with XE-991 block (Cerina et al., 2015). Our results are in good agreement with these previously observed effects of XE-991 in thalamocortical neurons, though they had not been previously demonstrated in motor thalamic areas. The complete lack of XE-991 effects following chronic 6-OHDA depletion we observed indicate a strong reduction of M-type current in this state. As supported by our modeling results, this effect can single-handedly account for the majority of our observations: a decrease in rheobase, an increase in spike rates, and an increase in LTS spikes following hyperpolarizing current injection. Interestingly, a homeostatic regulation of Kv7 channels has been previously observed in hippocampus and depends on L-type calcium channel signaling (Wu et al., 2008). Decreased BGMT spike rates following initial states of dopamine depletion would reduce L-type calcium currents and depotentiate M-type current according to this mechanism. KCNQ/Kv7 channels have also been localized to other key structures controlling brain rhythmic activity and neuronal synchronization including the $\mathrm{SNr}$ and the reticular nucleus of thalamus (Cooper et al., 2001). Thus, a more widespread function of these channels in controlling synchronization in BG circuits following dopamine depletion is quite possible.

The $\mathrm{I}_{\mathrm{H}}$ carried by HCN channels has been found to profoundly affect excitability and spiking regularity (Chan et al., 2004) as well as responses to synaptic inputs (Atherton et al., 2010) in a variety of cell types and it can undergo activity dependent regulation (Wang et al., 2002). This current is present in thalamus where it is known to regulate rhythmic activity patterns (Kanyshkova et al., 2009). Further, an HCN channelopathy has been found to be associated with dopamine depletion in globus pallidus neurons (Chan et al., 2011). When we tested BGMT neurons for changes in sag current following 6-OHDA treatment we identified a significant increase in sag (Fig. 3). While a detailed voltage-clamp analysis of HCN current was beyond the scope of our study, our modeling results suggest that the observed magnitude of sag increase cannot be accounted for by a decrease in M-current alone, suggesting an additional upregulation in $\mathrm{I}_{H}$ in the 6OHDA-treated condition. Following findings for subthalamic neurons, such upregulation is likely to lead to a shunting of inhibitory inputs that would limit T-type $\mathrm{Ca}^{2+}$ channel de-inactivation and reduce bursting (Atherton et al., 2010).

In conclusion, our finding of homeostatic changes in Mtype potassium current gives a clear indication that cellular changes in BGMT could play a considerable role in the changes of thalamic activity in Parkinsonian conditions, and notably increased bursting and synchrony. Because of the traditional view of the BGMT as a mere relay of a $B G$ rate code, changes in BGMT activity in behaving animals following dopamine depletion remain poorly studied to date. Recent studies from healthy rodents clearly indicate, however, that $\mathrm{VM}$, which is the biggest component structure of BGMT, shows a closed excitatory loop with ALM cortical activity and indeed cortical persistent activity during motor preparation collapses when VM is inactivated (Guo et al., 2017, 2018). Additionally, VM neurons show a complex set of activity changes during sensory cued motor decision-making tasks related to sensory cues, motor preparation, and motor execution (Guo et al., 2017; Catanese and Jaeger, 2020). Therefore, any changes in VM excitability and synchrony are likely to play an important role in motor preparation.

\section{References}

Albin RL, Young AB, Penney JB (1989) The functional-anatomy of basal ganglia disorders. Trends Neurosci 12:366-375.

Alexander GE, Crutcher MD (1990) Functional architecture of basal ganglia circuits: neural substrates of parallel processing. Trends Neurosci 13:266-271.

Alexander GE, DeLong MR, Strick PL (1986) Parallel organization of functionally segregated circuits linking basal ganglia and cortex. Annu Rev Neurosci 9:357-381.

Atherton JF, Kitano K, Baufreton J, Fan K, Wokosin D, Tkatch T, Shigemoto R, Surmeier DJ, Bevan MD (2010) Selective participation of somatodendritic HCN channels in inhibitory but not excitatory synaptic integration in neurons of the subthalamic nucleus. $J$ Neurosci 30:16025-16040.

Avila I, Parr-Brownlie LC, Brazhnik E, Castaneda E, Bergstrom DA, Walters JR (2010) Beta frequency synchronization in basal ganglia output during rest and walk in a hemiparkinsonian rat. Exp Neurol 221:307-319.

Barry PH (1994) JPCalc, a software package for calculating liquid junction potential corrections in patch-clamp, intracellular, epithelial and bilayer measurements and for correcting junction potential measurements. J Neurosci Methods 51:107-116.

Battefeld A, Tran BT, Gavrilis J, Cooper EC, Kole MHP (2014) Heteromeric $\mathrm{K}_{\mathrm{v}} 7.2 / 7.3$ channels differentially regulate action potential initiation and conduction in neocortical myelinated axons. $J$ Neurosci 34:3719-3732.

Beckstead RM, Domesick VB, Nauta WJH (1979) Efferent connections of the substantia nigra and ventral tegmental area in the rat. Brain Res 175:191-217.

Bosch-Bouju C, Hyland BI, Parr-Brownlie LC (2013) Motor thalamus integration of cortical, cerebellar and basal ganglia information: implications for normal and parkinsonian conditions. Front Comput Neurosci 7:163

Brazhnik E, Novikov N, McCoy AJ, Cruz AV, Walters JR (2014) Functional correlates of exaggerated oscillatory activity in basal ganglia output in hemiparkinsonian rats. Exp. Neurol 261C:563577.

Catanese J, Jaeger D (2020) Nigro-thalamic projection controls timing of action initiation. bioRxiv. doi: 10.1101/2020.01.12.903500.

Cebrian C, Parent A, Prensa L (2005) Patterns of axonal branching of neurons of the substantia nigra pars reticulata and pars lateralis in the rat. J Comp Neurol 492:349-369.

Cerina M, Szkudlarek HJ, Coulon $P$, Meuth $P$, Kanyshkova T, Nguyen XV, Göbel K, Seidenbecher T, Meuth SG, Pape HC, Budde T (2015) Thalamic Kv7 channels: pharmacological properties and activity control during noxious signal processing. $\mathrm{Br} \mathrm{J}$ Pharmacol 172:3126-3140.

Chan CS, Shigemoto R, Mercer JN, Surmeier DJ (2004) HCN2 and HCN1 channels govern the regularity of autonomous pacemaking 
and synaptic resetting in globus pallidus neurons. $J$ Neurosci 24:9921-9932.

Chan CS, Glajch KE, Gertler TS, Guzman JN, Mercer JN, Lewis AS, Goldberg AB, Tkatch T, Shigemoto R, Fleming SM, Chetkovich DM, Osten P, Kita H, Surmeier DJ (2011) HCN channelopathy in external globus pallidus neurons in models of Parkinson's disease. Nat Neurosci 14:85-92.

Chu HY, Atherton JF, Wokosin D, Surmeier DJ, Bevan MD (2015) Heterosynaptic regulation of external globus pallidus inputs to the subthalamic nucleus by the motor cortex. Neuron 85:364-376.

Chu HY, Mclver EL, Kovaleski RF, Atherton JF, Bevan MD (2017) Loss of hyperdirect pathway cortico-subthalamic inputs following degeneration of midbrain dopamine neurons. Neuron 95:13061318.e5.

Cooper EC, Harrington E, Jan YN, Jan LY (2001) M channel KCNQ2 subunits are localized to key sites for control of neuronal network oscillations and synchronization in mouse brain. $J$ Neurosci 21:9529-9540.

Davis GW (2006) Homeostatic control of neural activity: from phenomenology to molecular design. Annu Rev Neurosci 29:307-323.

DeLong MR (1990) Primate models of movement disorders of basal ganglia origin. Trends Neurosci 13:281-285.

Devergnas A, Chen E, Ma Y, Hamada I, Pittard D, Kammermeier S, Mullin AP, Faundez V, Lindsley CW, Jones C, Smith Y, Wichmann T (2016) Anatomical localization of Cav3.1 calcium channels and electrophysiological effects of T-type calcium channel blockade in the motor thalamus of MPTP-treated monkeys. J Neurophysiol 115:470-485.

Di Giovanni G, Grandi LC, Fedele E, Orban G, Salvadè A, Song W, Cuboni E, Stefani A, Kaelin-Lang A, Galati S (2020) Acute and chronic dopaminergic depletion differently affect motor thalamic function. Int J Mol Sci 21:2734.

Dougherty KA, Islam T, Johnston D (2012) Intrinsic excitability of CA1 pyramidal neurones from the rat dorsal and ventral hippocampus. J Physiol 590:5707-5722.

Edgerton JR, Jaeger D (2014) Optogenetic activation of nigral inhibitory inputs to motor thalamus in the mouse reveals classic inhibition with little potential for rebound activation. Front Cell Neurosci 8:36.

Eslamizade MJ, Saffarzadeh F, Mousavi SMM, Meftahi GH, Hosseinmardi N, Mehdizadeh M, Janahmadi M (2015) Alterations in CA1 pyramidal neuronal intrinsic excitability mediated by Ih channel currents in a rat model of amyloid beta pathology. Neuroscience 305:279-292.

Fan KY, Baufreton J, Surmeier DJ, Chan CS, Bevan MD (2012) Proliferation of external globus pallidus-subthalamic nucleus synapses following degeneration of midbrain dopamine neurons. J Neurosci 32:13718-13728.

Franklin KBJ, Paxinos G (2008) The mouse brain in stereotaxic coordinates, Ed 3. San Diego: Academic Press/Elsevier.

García-Cabezas MA, Martinez-Sanchez P, Sanchez-Gonzalez MA, Garzon M, Cavada C (2009) Dopamine innervation in the thalamus: monkey versus rat. Cereb Cortex 19:424-434.

Gentet LJ, Stuart GJ, Clements JD (2000) Direct measurement of specific membrane capacitance in neurons. Biophys J 79:314320.

Greene DL, Kang S, Hoshi N (2017) XE991 and linopirdine are statedependent inhibitors for Kv7/KCNQ channels that favor activated single subunits. J Pharmacol Exp Ther 362:177-185.

Guo K, Yamawaki N, Svoboda K, Shepherd GMG (2018) Anterolateral motor cortex connects with a medial subdivision of ventromedial thalamus through cell-type-specific circuits, forming an excitatory thalamo-cortico-thalamic loop via layer 1 apical tuft dendrites of layer 5B pyramidal tract type neurons. J Neurosci 38:8787-8797.

Guo ZV, Inagaki HK, Daie K, Druckmann S, Gerfen CR, Svoboda K (2017) Maintenance of persistent activity in a frontal thalamocortical loop. Nature 545:181-186.
Gutierrez C, Cox CL, Rinzel J, Sherman SM (2001) Dynamics of lowthreshold spike activation in relay neurons of the cat lateral geniculate nucleus. J Neurosci 21:1022-1032.

Ha GE, Lee J, Kwak H, Song K, Kwon J, Jung SY, Hong J, Chang GE, Hwang EM, Shin HS, Lee CJ, Cheong E (2016) The Ca(2+)-activated chloride channel anoctamin-2 mediates spike-frequency adaptation and regulates sensory transmission in thalamocortical neurons. Nat Commun 7:13791-13791.

Hines ML, Carnevale NT (1997) The NEURON simulation environment. Neural Comput 9:1179-1209.

Hu W, Tian C, Li T, Yang M, Hou H, Shu Y (2009) Distinct contributions of Nav1.6 and Nav1.2 in action potential initiation and backpropagation. Nat Neurosci 12:996-1002.

lavarone E, Yi J, Shi Y, Zandt B-J, O'Reilly C, Van Geit W, Rössert C, Markram H, Hill SL (2019) Experimentally-constrained biophysical models of tonic and burst firing modes in thalamocortical neurons. PLoS Comput Biol 15:e1006753.

Jahnsen H, Llinás R (1984a) lonic basis for the electro-responsiveness and oscillatory properties of guinea-pig thalamic neurones in vitro. J Physiol 349:227-247.

Jahnsen $H$, Llinás $R$ (1984b) Voltage-dependent burst-to-tonic switching of thalamic cell activity: an in vitro study. Arch Ital Biol 122:73-82.

Jahnsen H, Llinás R (1984c) Electrophysiological properties of guinea-pig thalamic neurones: an in vitro study. J Physiol 349:205-226.

Kanyshkova T, Pawlowski M, Meuth P, Dubé C, Bender RA, Brewster AL, Baumann A, Baram TZ, Pape H-C, Budde T (2009) Postnatal expression pattern of $\mathrm{HCN}$ channel isoforms in thalamic neurons: relationship to maturation of thalamocortical oscillations. J Neurosci 29:8847-8857.

Kasten MR, Rudy B, Anderson MP (2007) Differential regulation of action potential firing in adult murine thalamocortical neurons by $\mathrm{Kv} 3.2, \mathrm{Kv1}$, and SK potassium and $\mathrm{N}$-type calcium channels. J Physiol 584:565-582.

Kim J, Kim Y, Nakajima R, Shin A, Jeong M, Park AH, Jeong Y, Jo S, Yang S, Park H, Cho SH, Cho KH, Shim I, Chung JH, Paik SB, Augustine GJ, Kim D (2017) Inhibitory basal ganglia inputs induce excitatory motor signals in the thalamus. Neuron 95:1181-1196. e8.

Kovaleski RF, Callahan JW, Chazalon M, Wokosin DL, Baufreton J, Bevan MD (2020) Dysregulation of external globus pallidus-subthalamic nucleus network dynamics in parkinsonian mice during cortical slow-wave activity and activation. J Physiol 598:18971927.

Kuramoto E, Furuta T, Nakamura KC, Unzai T, Hioki H, Kaneko T (2009) Two types of thalamocortical projections from the motor thalamic nuclei of the rat: a single neuron-tracing study using viral vectors. Cereb Cortex 19:2065-2077.

Kuramoto E, Fujiyama F, Nakamura KC, Tanaka Y, Hioki H, Kaneko T (2011) Complementary distribution of glutamatergic cerebellar and GABAergic basal ganglia afferents to the rat motor thalamic nuclei. Eur J Neurosci 33:95-109.

Kuramoto E, Ohno S, Furuta T, Unzai T, Tanaka YR, Hioki H, Kaneko $T$ (2015) Ventral medial nucleus neurons send thalamocortical afferents more widely and more preferentially to layer 1 than neurons of the ventral anterior-ventral lateral nuclear complex in the rat. Cereb Cortex 25:221-235.

Llinás R, Jahnsen H (1982) Electrophysiology of mammalian thalamic neurones in vitro. Nature 297:406-408.

Llinás RR, Steriade M (2006) Bursting of thalamic neurons and states of vigilance. J Neurophysiol 95:3297-3308.

Lobb CJ (2014) Abnormal bursting as a pathophysiological mechanism in Parkinson's disease. Basal Ganglia 3:187-195.

Lobb CJ, Jaeger D (2015) Bursting activity of substantia nigra pars reticulata neurons in mouse parkinsonism in awake and anesthetized states. Neurobiol Dis 75C:177-185.

Lundblad M, Picconi B, Lindgren H, Cenci MA (2004) A model of LDOPA-induced dyskinesia in 6-hydroxydopamine lesioned mice: 
relation to motor and cellular parameters of nigrostriatal function. Neurobiol Dis 16:110-123.

Magill PJ, Bolam JP, Bevan MD (2001) Dopamine regulates the impact of the cerebral cortex on the subthalamic nucleus-globus pallidus network. Neuroscience 106:313-330.

Magnin M, Morel A, Jeanmonod D (2000) Single-unit analysis of the pallidum, thalamus and subthalamic nucleus in parkinsonian patients. Neuroscience 96:549-564.

Mallet N, Pogosyan A, Marton LF, Bolam JP, Brown P, Magill PJ (2008) Parkinsonian beta oscillations in the external globus pallidus and their relationship with subthalamic nucleus activity. $\mathrm{J}$ Neurosci 28:14245-14258.

McCormick DA (1989) Cholinergic and noradrenergic modulation of thalamocortical processing. Trends Neurosci 12:215-221.

McCormick DA, Prince DA (1986) Acetylcholine induces burst firing in thalamic reticular neurones by activating a potassium conductance. Nature 319:402-405.

Mclver EL, Atherton JF, Chu HY, Cosgrove KE, Kondapalli J, Wokosin D, Surmeier DJ, Bevan MD (2019) Maladaptive downregulation of autonomous subthalamic nucleus activity following the loss of midbrain dopamine neurons. Cell Rep 28:992-1002.e4.

Murer MG, Riquelme LA, Tseng KY, Pazo JH (1997) Substantia nigra pars reticulata single unit activity in normal and 60HDA-lesioned rats: effects of intrastriatal apomorphine and subthalamic lesions. Synapse 27:278-293.

Narayanan R, Johnston D (2007) Long-term potentiation in rat hippocampal neurons is accompanied by spatially widespread changes in intrinsic oscillatory dynamics and excitability. Neuron 56:10611075.

Noam Y, Bernard C, Baram TZ (2011) Towards an integrated view of HCN channel role in epilepsy. Curr Opin Neurobiol 21:873-879.

Pifferi S, Dibattista M, Menini A (2009) TMEM16B induces chloride currents activated by calcium in mammalian cells. Pflugers Arch 458:1023-1038.

Ramcharan EJ, Gnadt JW, Sherman SM (2000) Burst and tonic firing in thalamic cells of unanesthetized, behaving monkeys. Vis Neurosci 17:55-62.
Sawyer SF, Young SJ, Groves PM (1989) Quantitative Golgi study of anatomically identified subdivisions of motor thalamus in the rat. $J$ Comp Neurol 286:1-27.

Sheets PL, Suter BA, Kiritani T, Chan CS, Surmeier DJ, Shepherd GMG (2011) Corticospinal-specific HCN expression in mouse motor cortex: I(h)-dependent synaptic integration as a candidate microcircuit mechanism involved in motor control. J Neurophysiol 106:2216-2231.

Sherman SM, Guillery RW (2002) The role of the thalamus in the flow of information to the cortex. Phil Trans R Soc Lond B Biol Sci 357:1695-1708.

Turrigiano G (2011) Too many cooks? Intrinsic and synaptic homeostatic mechanisms in cortical circuit refinement. Annu Rev Neurosci 34:89-103.

Walters JR, Hu D, Itoga CA, Parr-Brownlie LC, Bergstrom DA (2007) Phase relationships support a role for coordinated activity in the indirect pathway in organizing slow oscillations in basal ganglia output after loss of dopamine. Neuroscience 144:762-776.

Wang J, Chen S, Nolan MF, Siegelbaum SA (2002) Activity-dependent regulation of HCN pacemaker channels by cyclic AMP: signaling through dynamic allosteric coupling. Neuron 36:451-461.

Williams SR, Christensen SR, Stuart GJ, Häusser M (2002) Membrane potential bistability is controlled by the hyperpolarization-activated current $\mathrm{I}(\mathrm{H})$ in rat cerebellar Purkinje neurons in vitro. J Physiol 539:469-483.

Wilson CJ, Bevan MD (2011) Intrinsic dynamics and synaptic inputs control the activity patterns of subthalamic nucleus neurons in health and in Parkinson's disease. Neuroscience 198:54-68.

Womack MD, Chevez C, Khodakhah K (2004) Calcium-activated potassium channels are selectively coupled to P/Q-type calcium channels in cerebellar Purkinje neurons. J Neurosci 24:88188822.

Wu WW, Chan CS, Surmeier DJ, Disterhoft JF (2008) Coupling of Ltype $\mathrm{Ca} 2+$ channels to KV7/KCNQ channels creates a novel, activity-dependent, homeostatic intrinsic plasticity. J Neurophysiol 100:1897-1908. 